\title{
Corneal Nerves in Health and Disease
}

\author{
Brittany Shaheen, May Bakir, and Sandeep Jain ${ }^{*}$ \\ Corneal Neurobiology Laboratory, Department of Ophthalmology and Visual Sciences, College of \\ Medicine, University of Illinois at Chicago, Chicago, IL
}

\section{Abstract}

Corneal nerves are responsible for the sensations of touch, pain, and temperature and play an important role in the blink reflex, wound healing, and tear production and secretion. Corneal nerve dysfunction is a frequent feature of diseases that cause opacities and result in corneal blindness. Corneal opacities rank as the second most frequent cause of blindness. Technological advances in in vivo corneal nerve imaging, such as optical coherence tomography and confocal scanning, have generated new knowledge regarding the phenomenological events that occur during reinnervation of the cornea following disease, injury, or surgery. The recent availability of transgenic neurofluorescent murine models has stimulated the search for molecular modulators of corneal nerve regeneration. New evidence suggests that neuro-regenerative and inflammatory pathways in the cornea are intertwined. Evidence-based treatment of neurotrophic corneal diseases includes using neuro-regenerative (blood component-based and neurotrophic factors), neuroprotective, and ensconcing (bandage contact lens and amniotic membrane) strategies and avoiding antiinflammatory therapies, such as cyclosporine and corticosteroids.

\section{Keywords}

corneal nerves; nerve regeneration; neurotrophic keratitis; inflammation; neuropathic pain

\section{A. INTRODUCTION}

The cornea is the most densely innervated structure in the human body. In 1831, Schlemm discovered nerves in the cornea. Prior to this discovery, the cornea was thought to be entirely without nerves. Several years after Schlemm's original observation, Bochdalek dissected the ciliary nerves within the cornea and found that they divided into corneal and iris branches and that the corneal nerves entered at the anterior thickness. ${ }^{29,198}$ Corneal nerves are responsible for sensations of touch, pain, and temperature and play an important role in blink reflex, wound healing, ${ }^{28}$ and tear production and secretion. ${ }^{88,171}$ Numerous studies have established that corneal nerve dysfunction is a frequent pathobiological feature

\footnotetext{
(C) 2013 Elsevier Inc. All rights reserved.

*Corresponding Author: Sandeep Jain MD, Department of Ophthalmology and Visual Sciences, University of Illinois at Chicago, 1855 W. Taylor Street, Chicago, IL 60612. Phone: (312) 413-8936; Fax: (312) 996-7770; jains@uic.edu.

Publisher's Disclaimer: This is a PDF file of an unedited manuscript that has been accepted for publication. As a service to our customers we are providing this early version of the manuscript. The manuscript will undergo copyediting, typesetting, and review of the resulting proof before it is published in its final citable form. Please note that during the production process errors may be discovered which could affect the content, and all legal disclaimers that apply to the journal pertain.
} 
of corneal diseases that cause opacities and result in blindness. Approximately 285 million people worldwide suffer from impaired vision; of these, 2.85 million have corneal opacities. ${ }^{178}$ Likewise, of the 39.3 million worldwide who are blind, in 1.57 million this is the result of corneal opacities. ${ }^{178}$ In conditions that cause corneal blindness, sensation is frequently diminished or absent because of nerve dysfunction or degeneration. Several infectious and non-infectious inflammatory corneal diseases can lead to lost or compromised innervation and result in neurotrophic keratopathy and blindness. ${ }^{52,216}$ Although the subbasal nerve density is variably reduced in these inflammatory corneal diseases, ${ }^{24,52,216,219}$ the number of antigen presenting dendritic cells is increased, 52,216 suggesting that the immune and nervous system pathways in the cornea are intertwined.

Despite the high prevalence of corneal blindness and nerve dysfunction and the clinical need to promote corneal nerve regeneration in neurotrophic corneas, there are relatively few specific therapeutic interventions. Therefore, it is not surprising that the National Eye Institute (NEI) Cornea Disease Panel in its July, 2012, Vision Research: Needs, Gaps and Opportunities document highlights the need to develop novel agents capable of stimulating appropriate corneal nerve regeneration. Additionally, this panel has emphasized the importance of correlating the molecular and structural composition of corneal nerves with their function. These recommendations build upon those of the NEI Workshop on Ocular Pain and Sensitivity. This panel concluded that the role of neurons in the health, healing, scarring, and immunology of the cornea, as well as the responsible molecular and cellular mechanisms, has yet to be determined. Therefore, further understanding the molecular and cellular changes that occur in primary sensory neurons as a result of disease or trauma, including their regenerative mechanisms, constitute a high priority.

\section{B. CORNEAL NERVE BIOLOGY}

\section{B1. Corneal nerve organization}

B1a. Corneal nerve anatomy-In the cornea, 50-450 sensory trigeminal neurons transmit nerve fibers via the ophthalmic division of the trigeminal nerve (cranial nerve $\mathrm{V}$ ) and terminate in free nerve endings in the corneal epithelium. ${ }^{156}$ From trigeminal ganglion cells, nerve fibers travel suprachoroidally and branch to form nerve bundles that come to rest uniformly around the corneoscleral limbus to form the limbal plexus. ${ }^{6}$ Autonomic innervation may travel along with these nerve fibers, though it is believed to be scarce (sympathetic) or unknown (parasympathetic). ${ }^{156}$ Stromal nerve trunks arise from the limbal plexus and enter the peripheral corneal stroma radially at a depth of $293 \pm 106 \mu \mathrm{m}$ before progressing anteriorly. ${ }^{138}$ There are discrepancies among studies regarding the number of stromal nerve bundles located at the corneo-scleral junction, perhaps due to differences in the points where the nerve bundles are imaged and counted. ${ }^{87}$ The stromal nerves enter the cornea like a tree dividing into several branches in the peripheral area close to the limbus. Because the number of nerve divisions increases in relation to the distance from the corneoscleral junction, more nerves will appear to be present than what are really in the cornea. ${ }^{19}$ The reported average number of nerve bundles entering the human cornea ranges from 33 to 71. ${ }^{6,87,138}$ 
Stromal nerve trunks are comprised of 900-1200 myelinated and unmyelinated axons with diameters of $0.5-5 \mu \mathrm{m} .{ }^{160}$ Although myelinated NF-200 positive nerve fibers in the periphery of the murine cornea are present, ${ }^{165}$ the peripheral and central nerve fibers of the human cornea are nociceptive A $\delta$ and C fibers. ${ }^{158}$ Prototypical A $\delta$ fibers are myelinated straight nerves with a relatively large diameter, whereas $\mathrm{C}$ fibers are smaller, beaded fibers with no myelination. ${ }^{160}$ In the stroma, beaded fibers may arise from straight fibers, ${ }^{157}$ suggesting an overlap in morphology or the presence of multiple fiber types in straight nerve bundles. One millimeter after entering the corneal limbus, corneal nerve fibers lose their perineurium and myelin sheaths, and continue on surrounded solely by Schwann cells. ${ }^{156}$ As in other peripheral innervation, non-myelinating Schwann cells "wrap" several C-type nerve fibers together to form a "Remak bundle." 48,156 These Schwann cells and Remak bundles are essential for maintenance and function of unmyelinated axons and nociceptors and may assist in electrical conduction. ${ }^{48}$ In the stroma, nerves organize in parallel to collagen lamellae, branch into smaller fascicles as they proceed toward the superficial stroma, and form interconnections within the stroma to create the anterior stromal plexus. ${ }^{87,156,157}$ In other words, nerve density increases while nerve diameter thins as one moves anteriorly through the stroma. A small number of stromal nerves terminate as free nerve endings, ${ }^{137}$ whereas others directly innervate keratocytes. ${ }^{157}$ Such direct keratocyte innervation alludes to the complex dependency of these tissue types; in fact, a trophic interdependence exists between ocular tissues and their sensory innervation. ${ }^{23}$ Additional stromal nerves defasciculate as they progress anteriorly towards the anterior stroma, subbasal, and epithelial layers of the cornea.

The corneal epithelium derives innervation from the subbasal nerve plexus. Although the existence of the epithelial nerve plexus has been known for more than a century, ${ }^{93,174}$ until recently its detailed architecture and exact location was unclear. ${ }^{87} \mathrm{He}$ et al. have shown that the plexus forms a delicate three-dimensional network in the corneal epithelium. ${ }^{87}$ The plexus originates from the branches of the peripheral stromal nerves. The tips of the stromal nerves penetrate the Bowman layer into the epithelium, predominantly in the peripheral cornea, and give rise to long bundles that run from the periphery to the center close to the subbasal epithelia like wavy lines. Along their course, these long nerve bundles divide into numerous smaller branches that connect to each other, constituting a delicate nerve network within the epithelium. These nerves form a whorl-like pattern approximately $1-2.5 \mathrm{~mm}$ inferonasal to the corneal apex. ${ }^{138,181}$ The subbasal plexus nerves are thinner than the stromal nerves, and seem to be comprised predominantly of C fibers. ${ }^{158}$ At the level of the subbasal plexus, straight A $\delta$ fibers within the basal epithelial cell layer course parallel to the corneal surface, and only beaded unmyelinated $\mathrm{C}$ fibers travel for a short distance along the subbasal plexus before turning upward and terminating perpendicularly just beneath the epithelial surface as free nerve endings ${ }^{157}$ (Figure 1). Density of epithelial nerves is greater centrally than peripherally. ${ }^{87}$ Free nerve endings display a density of approximately 605.8 terminals $/ \mathrm{mm}^{2}$ in central epithelial suprabasal cells, ${ }^{138}$ resulting in a large receptive field overlap. ${ }^{160}$ Both the subbasal plexus and epithelial nerves display unique centripetal migration during development (in tandem with epithelial cells). ${ }^{13}$ These nociceptive fibers collectively respond to mechanical, thermal, and chemical stimuli. Examples of chemical stimuli include acetylcholine (ACh), prostaglandins, and bradykinin. ${ }^{23}$ As discussed by 
Belmonte et al., ${ }^{21}$ some fibers are stimulus-specific, although the majority are polymodal. Approximately $20 \%$ of corneal nociceptors are A $\delta$ mechanoreceptors that generate acute pain. Another approximately $70 \%$ are polymodal. The remaining $10 \%$ are $\mathrm{C}$ fiber cold receptors. A separate, "silent" class of nociceptors that are activated only by local inflammation may also exist. Collectively, these fiber types have been implicated in animal models of neuropathic pain, possibly via expression of transient receptor potential (TRP) family members such as the TRP vanilloid receptor (TRPV1), ${ }^{93,214}$ which may be absent from A $\delta$ mechanoreceptors. ${ }^{159}$ In the cornea, inflammatory cells may trigger neuropathic pain, or extracellular chemicals may act on TRPV1 to produce pathologically sensitized signaling. ${ }^{159}$ In addition to anatomical location and nerve fiber type, corneal nerve fibers can be classified based on their neurochemical profiles and have been studied in response to neurotrophic factors.

The various nerve populations in the cornea are distinguishable by their neurochemical markers (Table 1). Some neurochemical markers also serve as neurotrophic factors. Animal studies show neurotrophic factors assist in maintenance of the healthy cornea and modulate wound repair. ${ }^{162}$ For example, substance P (SP), released directly from C fibers following inflammation ${ }^{21}$ in synergism with epidermal growth factor (EGF), stimulates epithelial proliferation and wound healing. Neuropeptide Y (NPY) has a similar role elsewhere in the body. ${ }^{106} \mathrm{SP}$ and calcitonin gene-related peptide (CGRP) are involved in neurogenic inflammation. ${ }^{21}$ Other corneal neurotrophic factors include nerve growth factor (NGF), brain-derived neurotrophic factor (BDNF), neurotrophin (NT)-3, Semaphorin (Sema) 3A, 3F, and 7A, Slits 1-3, Netrin 2, and Ephrin (Eph) B2. ${ }^{113,164}$ A patterned expression of factors and receptors is observed between corneal nerves and epithelium. ${ }^{188}$ Loss of neurotrophic signaling negatively impacts corneal nerve function. For example, inactivation of tyrosine receptor kinase (Trk) A, a high-affinity NGF tyrosine kinase receptor, results in decreases in nociceptive neurons, stromal nerves, and corneal epithelium, as well as a reduced response to noxious stimuli. ${ }^{56}$ Changes in neurotrophic signaling drive corneal nerve development and may underlie changes in corneal nerves during the aging process.

B1b. Corneal nerves in development and aging-Corneal nerve development has been predominantly studied in chicks, with fewer studies in mice. Corneal nerves derive from neural crest cells residing in the ophthalmic lobe of the trigeminal ganglion. ${ }^{133}$ The proto-corneal neural crest derivatives migrate with placode-derived cells to the periocular mesenchyme, possibly led by EphA3 receptor kinase axon guidance. ${ }^{104,133}$ In chicks, corneal nerve migration is differentially regulated by Sema3A and Slit2 interactions with their respective receptors, Neuropilin (Npn)-1 and transmembrane roundabout (ROBO). ${ }^{113}$ Negative regulation coincides with pericorneal nerve ring development, allowing nerve fascicles to accumulate and extend dorsally and ventrally around the cornea to cover uniformly greater than three-quarters of its circumference. ${ }^{134}$ (Figure 2) This is followed by positive regulation allowing corneal nerves to invade the stroma. ${ }^{113,134}$ Extracellular levels of highly sulfated keratan sulfate proteoglycans (KSPGs) also regulate the initial process of invasion. ${ }^{46}$ Following stromal invasion, further nerve bifurcation leads to peripheral corneal innervation in chicks by embryonic day 10 (E10), and guarantees the entire circumference is innervated by E15. ${ }^{134}$ Complete penetration of corneal nerves to the center of the cornea 
with branching into the corneal epithelium is achieved by E16. ${ }^{18}$ In mice nerve bundles directly innervate the cornea under the regulation of Sema3A/Npn1 and Sema3F/Npn2 without first forming a pericorneal nerve ring. ${ }^{146,147}$ Nerve development relies on nerve bundles from all four quadrants of the eye and progresses from a radial pattern to a more central orientation, branching to form a subbasal "swirl" network akin to the subbasal plexus in human cornea. ${ }^{146}$ In humans, both the subbasal plexus and epithelial nerves display centripetal migration during development (in tandem with epithelial cells). ${ }^{13}$ The radial progression of innervation may be equivalent to the chick pericorneal nerve ring.

On the opposite spectrum of corneal nerve development are corneal nerves during the aging process. It is unknown whether healthy corneal nerves exhibit uncompromised function throughout life or if they are subject to the typical degenerative processes of aging. Current research yields conflicting results. Data from tandem scanning and slit scanning confocal microscopy suggest that corneal nerves (particularly subbasal nerve density) are maintained in an age-independent manner, ${ }^{64,91,183}$ whereas laser scanning confocal and fluorescence microscopy demonstrate pronounced loss of corneal epithelial nerve terminals and subbasal nerve fiber density with age. ${ }^{87,169}$ Increased subbasal nerve tortuosity has also been observed with age. ${ }^{183}$ Such mixed results are most likely due to differences in imaging techniques (discussed in greater detail below). An alternative measure of age-related corneal nerve changes is testing the functionality of corneal nerves. Using a Cochet-Bonnet aesthesiometer to test A $\delta$ fiber mechanical sensitivity, corneal sensitivity seems to decrease gradually with age, beginning in the periphery and progressing centrally. ${ }^{160,192}$ Using the Belmonte non-contact aesthesiometer, which measures mechanical stimulation to A $\delta$ fibers and $\mathrm{C}$ fibers as well as thermo- and chemoreceptor sensitivity in $\mathrm{C}$ fibers, corneal sensitivity begins to decline in the patient's second decade, with major changes (presumably those registered by the Cochet-Bonnet aesthesiometer) becoming apparent by age $50 .{ }^{160} \mathrm{It}$ remains unknown whether $\mathrm{C}$ fibers are preferentially targeted earlier in aging, but these findings suggest a dual decline in $\mathrm{A} \delta$ and $\mathrm{C}$ fiber sensitivity with age.

\section{B2. Imaging corneal nerves}

B2a. In vivo Confocal Microscopy (IVCM) and Optical Coherence Tomography (OCT)—As reviewed by others, ${ }^{51,180}$ IVCM has been used to assess corneal nerves in healthy subjects, contact lens wearers, keratoconus patients, dry eye disease, diabetics, and other pathologic states. IVCM findings clinically correlate to slit-lamp microscopy and postoperative findings and highlight the utility of consistent imaging methodology. ${ }^{51,180}$

Several confocal microscopes exist that image corneal nerves. Some instruments utilize a confocal slit principle, such as the ConfoScan 4 (Nidek, Japan), whereas in tandem scanning microscopes, images are captured using a rotating Nipkow disc. Other instruments, such as the Rostock Cornea Module-HRT (Heidelberg, Germany), utilize a laser. Figure 3 shows sample imaging from these modalities. Automated and manual tracing of nerves in confocal images have well-correlated length estimates, but discrepancies exist in image quantification, including minimum nerve lengths and maximum number of nerves compared to "most representative" images. ${ }^{180}$ Differences also arise due to confocal design. ${ }^{180} \mathrm{~A}$ tandem scanning microscope has a narrow depth of field $(11 \mu \mathrm{m})$, which reduces brightness and contrast, as well as limited magnification such that structures $<5 \mu \mathrm{m}$ are difficult to 
resolve. ${ }^{65}$ The tandem scanning method yields a lower subbasal nerve plexus density than other confocal microscopes. ${ }^{180}$ A slit scanning microscope with a wider aperture of $300 \mu \mathrm{m}$ (ConfoScan4 Nidek Technologies) compared to the tandem scanning aperture of $30 \mu \mathrm{m}$ produces images of higher contrast, brightness, sharpness, and detail. ${ }^{65} \mathrm{~A}$ combination of high light throughput and magnification, lower resolution, and variable optical section thickness allows visualization of subbasal nerves and possibly sub-Bowman stromal nerves, which are unlikely to be seen in tandem scanning microscopy. ${ }^{61} \mathrm{~A}$ third type of confocal microscope, a laser scanning microscope, offers high-contrast, high quality images with the greatest resolution. ${ }^{65}$ Laser-scanning shows whorl-like subbasal nerves (architecture not seen with slit-scanning) ${ }^{51}$ and increased nerve densities. ${ }^{65,181}$ A comparison of confocal microscopy modalities can be found in Table 2. Recently, optical coherence tomography (OCT) has been investigated as an alternative to confocal microscopy for corneal imaging. OCT is typically used to assess tissue thickness, such as that of the cornea and retina. Fullfield (FF) OCT produces high-resolution images of corneal nerve fibers. ${ }^{4}$

Corneal epithelial innervation, as estimated by confocal microscopes, is 15-20 times greater than that found by immunohistochemical staining techniques. ${ }^{87}$ This discrepancy may be partly because IVCM images of human corneas are recorded at or near the corneal apex in areas most densely innervated. ${ }^{87}$

B2b. Transgenic neurofluorescent murine models-Neurofluorescent mouse models allow in vivo visualization of sensory nerves. The thyl-YFP transgenic mouse is a neurofluorescent murine model in which yellow fluorescent protein (YFP) is tagged to the thyl gene promoter. ${ }^{235}$ (Figure 4) In the thy1-YFP mouse model a proportion of sensory nerves are fluorescent, so axonal regeneration and degeneration can be visualized and quantified in vivo. Yu and Rosenblatt were the first to use these mice for studying corneal nerves. ${ }^{235}$ They reported that only half of the corneal subbasal nerves are YFP-labeled. In addition, changes in the density and pattern of the YFP-labeled subbasal nerve plexus may occur with sequential stereofluorescence microscope imaging without any intervention. ${ }^{165}$ Therefore, investigation of the subbasal nerve plexus should account for any limitations inherent in the thyl-YFP mouse model as well in vivo visualization methodology limitations. In contrast to the subbasal nerve plexus, nearly all stromal nerves can be visualized in the thyl-YFP mouse model. ${ }^{235}$ The stromal nerves have YFP-labeled and unlabeled fibers; however, there are enough YFP-labeled fibers in each stromal nerve to allow their visualization. The pattern and density of stromal nerves remains constant during sequential visualization. ${ }^{165,197}$ YFP fluorescence disappears in transected stromal nerves distal to the transection site and reappears in regenerating neurites. ${ }^{235}$ By visualizing the density and pattern of regenerating YFP-labeled neurites, it is possible to investigate the neurotrophic potential of molecular or pharmacological interventions on stromal nerve regeneration. ${ }^{163}$

\section{B3. Signs and symptoms of corneal nerve dysfunction}

Several methods are available for testing corneal nerve function. Direct measures employ aesthesiometry, whereas indirect tests rely on lacrimation and fluorescent dyes. The CochetBonnet contact aesthesiometer (CBA) primarily detects mechano-nociceptor response to an invasive mechanical stimulus, thereby quantifying $\mathrm{A} \delta$ fiber function while $\mathrm{C}$ fiber activity is 
undetermined. ${ }^{160}$ The tip of the aesthesiometer filament stimulates nerve terminal endings over a test area of $0.011 \mathrm{~mm}^{2}$ in the cornea, corresponding to approximately 6-77 terminal endings per square millimeter (based on current estimates of terminal nerve fiber density). ${ }^{138,156,160}$ Corneal sensitivity is highest in the central cornea, ${ }^{192}$ thus requiring appropriate placement of the aesthesiometer tip for accurate results. The direct contact of the CBA can damage the corneal epithelium, ${ }^{160}$ which may be a source of decreased sensitivity from loss of nerve endings or increased sensitivity due to pathologic nerve damage. The Belmonte non-contact corneal aesthesiometer (NCCA) non-invasively stimulates corneal nerves over a test area of $0.196 \mathrm{~mm}^{2}$ with variable force, composition, and temperature using a pulse (or "puff") of air to allow multimodal testing (mechanical, chemical, and thermal stimuli). ${ }^{21,160} \mathrm{NCCA}$ testing provides more information regarding polymodal and thermal receptor functionality, as well as C fibers, than does the CBA. ${ }^{160}$ The NCCA is more accurate and sensitive than the CBA. ${ }^{160}$

Indirect tests of corneal nerve function reveal general information about the state of corneal nerves. Lacrimation tests (Schirmer and phenol red thread tests) assess tear production, whereas vital dyes reveal damaged corneal epithelium. Dyes include fluorescein, rose bengal, and lissamine green. Fluorescein is often preferred for corneal epithelial staining and may identify contact lens-associated pathologies without requiring further diagnostic intervention, while lissamine green stains correlate highly with dry eye syndromes. ${ }^{60} \mathrm{In}$ addition to direct and indirect assessments of corneal nerve function, patients' symptoms reflect ocular surface distress.

Corneal nerve damage may be associated with symptoms such as ocular irritation, photophobia, or pain; ${ }^{23}$ however, symptoms may not correlate with the degree of ocular surface disease. Because of hypoesthesia, patients with neurotrophic keratitis may have significant ocular surface disease, but may be quite comfortable. ${ }^{226}$ Alternatively, some patients report significant pain in the absence of ocular surface disease. This neuropathic pain typically follows nerve damage, for example, from surgical transection such as LASIK or cataract surgery. ${ }^{21}$

\section{B4. Modulators of corneal nerve growth and function}

\section{B4a. Neurotrophins}

Nerve growth factor (NGF): As discovered through in vitro and in vivo animal studies, nerve growth factor (NGF) is critical for corneal nerve survival and maintenance, as well as axonal branching and elongation, neuronal sprouting, and regeneration following nerve damage. ${ }^{135}$ Multiple studies have shown that NGF augments corneal wound healing, as evidenced by recovery of corneal sensitivity and photophobia in association with increased NGF and corneal epithelium healing. ${ }^{9,156}$ NGF is expressed in the cornea during reinnervation after nerve surgical transection. ${ }^{42}$ Nerve regeneration may be partially attributable to neurogenic inflammation, such as interleukin (IL)-1-induced NGF. 120,129 NGF reportedly promotes the human cornea's healing process via pro-neural molecules like SP and insulin-like growth factor (IGF)-1, as well as by stimulation of epithelial proliferation. ${ }^{36,156}$ Interestingly, NGF expression is elevated in inflammatory conditions like dry eye, and this elevation in NGF may contribute to the pathogenesis of dry eye. ${ }^{121}$ 
NGF also has potent antiviral properties and restricts viral infections like HSV-1 to the cornea. 118

Brain-derived neurotrophic factor (BDNF): Similar to NGF, brain-derived neurotrophic factor (BDNF) is found in corneal epithelium and stromal keratocytes and is believed to also originate from corneal sensory neurons. ${ }^{156,234}$ In vitro studies of human cell lines and in vivo animal models demonstrate that BDNF is capable of inducing central and peripheral nerve growth and regeneration, ${ }^{45,132}$ and stimulates other neurotrophins (including NT-4/5) and neurotrophic factors (such as Gap-43) to achieve neurite re-growth. ${ }^{112}$ BDNF is neuroprotective in retinal ganglion cells, possibly via delayed apoptosis of neurons. 98 Although BDNF expression has been observed after experimental flap surgery in putative corneal stromal and/or inflammatory cells in a positive association with neurite extension, its exact role related to corneal nerves is unclear. 42

Glial cell-derived neurotrophic factor (GDNF): Glial cell-derived neurotrophic factor (GDNF) is a pro-neural member of the TGF- $\beta$ superfamily. ${ }^{156,234}$ Elsewhere in the nervous system, GDNF applied to in vitro chick dorsal root ganglia explants promotes axonal elongation. ${ }^{135}$ GDNF is expressed in human corneal stromal keratocytes and may operate similarly to or synergistically with NGF by triggering gene transcription governing epithelial cell migration and wound healing. ${ }^{135,233,234}$ It has been shown that topical GDNF produces complete epithelial healing in a patient with a progressive neurotrophic ulcer. ${ }^{233}$

Neurotrophins 3, 4/5 (NT-3, -4): In the cornea, neurotrophin-3 (NT-3) is transcribed in epithelial cells and stromal keratocytes. ${ }^{234}$ In vitro mouse studies show that elsewhere in the nervous system, NT-3 regulates neuronal cell differentiation and survival and induces neurite outgrowth in mouse neural stem cells. ${ }^{128}$ NT-3 is also a chemoattractant for dorsal root ganglion cells. ${ }^{185}$ A recent animal model, however, demonstrated only minimal changes in NT-3 gene expression following surgical transection of corneal nerves. ${ }^{42}$ These data suggest that NT-3 may be preferentially involved in corneal epithelial maintenance. NT-4 is also present in corneal epithelium and is a neurotrophic factor that may be involved in the regulation of stromal keratocytes by epithelial cells. ${ }^{234}$ In development, NT-4 collapses neural growth cones and causes transient neural growth inhibition in NGF- and NT-3-dependent rat dorsal root ganglion cells. ${ }^{185}$ NT-4 is neuroprotective, however, in rat explants of retinal ganglion cells and enhances neurite outgrowth in the retina. ${ }^{45}$ Little is known about the specific roles of NT-3 and -4 with regards to corneal nerves.

\section{B4b. Neurotrophic factors, nerve guidance factors, and regeneration- associated genes}

Vascular endothelial growth factor (VEGF): As shown in murine models, vascular endothelial growth factor (VEGF) and its receptors are minimally present in healthy and damaged corneas, and VEGF is upregulated in the injured cornea. ${ }^{127,236}$ VEGF is proneural via neurotrophic and neuroprotective actions. Trigeminal neurons respond to and secrete VEGF, and VEGF is required for efficient corneal nerve regeneration. 127,236 VEGF supplementation promotes trigeminal nerve repair, and abrogation of VEGF signaling reduces corneal nerve growth. Because topical VEGF neutralization using bevacizumab eye 
drops has been proposed as a treatment for corneal neovascularization, the finding that VEGF signaling modulates corneal nerve repair warrants consideration of the anti-neuronal effects of antiangiogenesis treatment in the cornea. In the normal murine cornea, topical application of bevacizumab eye drops does not reduce nerve fiber density. ${ }^{30}$ Topical application of bevacizumab eye drops to wounded murine corneas, however, results in VEGF depletion, NGF downregulation, and development of a neurotrophic keratitis-like ulcer. ${ }^{109,236}$ In humans, topical bevacizumab is associated with increased corneal epitheliopathy. 111

Semaphorins: Semaphorins were identified originally as axon guidance factors. Through animal models, it now is known that several semaphorins, the "immune semaphorins," are involved in various phases of the immune response by regulating immune cell contacts or cell migration. ${ }^{173,207}$ These "immune semaphorins" include Sema3A, 4A, 4D, 6D, and 7A. ${ }^{173}$ Unlike many semaphorins that act as repulsive guidance cues, the GPI-anchored membrane-associated Sema7A is neither an axonal repellent nor attractant. ${ }^{179}$ Instead, it promotes axon outgrowth in a direction that is likely dictated by other cues. Sema7A is expressed constitutively in the cornea, predominantly concentrated in the epithelium with less expression in the stroma. ${ }^{164}$ Corneal Sema7A expression increases after nerve transecting lamellar surgery and is localized near the regenerating nerve fronds. ${ }^{164}$ Sema7A induces trigeminal ganglion cell neurite growth in vitro as potently as NGF. ${ }^{164}$ Additionally, it induces significant nerve regeneration in vivo, accompanied by significant inflammatory cell influx to the cornea. ${ }^{164}$ This suggests that Sema7A acts as a neurotrophic factor in the cornea that can also influence inflammatory processes. In contrast to Sema7A, Sema3A is a negative regulator of innervation. During development, Sema3A repulses innervation and collapses neural growth cones. ${ }^{113}$ Blocking Sema3A results in overwhelmingly disorganized corneal innervation during development. ${ }^{113}$ Sema3A also blocks the positive neuromodulator VEGF and repulses growing nerves in vitro. ${ }^{82} \mathrm{~A}$ recent study suggests that blocking Sema3A aids corneal nerve regeneration into donor tissue and recovery of corneal nerve sensation in a mouse model of corneal transplantation. ${ }^{175}$ Although the role of Sema3A in the human cornea is unclear, it is possible that Sema3A negatively counterbalances positive VEGF neural regulation to ensure controlled neural regeneration after wounding.

Growth-associated protein 43 (GAP-43): Growth-associated protein 43 (GAP-43) is a rapidly transported axonal protein induced after nerve injury and localized to the axonal growth cone. ${ }^{200}$ Studies in animals show GAP-43 is constitutively expressed in corneal sensory nerves, and GAP-43 levels are elevated in response to infection with HSV-1 and for approximately 2 weeks following surgical transection. ${ }^{42,139,140}$ GAP-43 plays a role in neural regeneration stimulated by BDNF and NT-4/5. ${ }^{112}$ In contrast to the effect of BDNF on GAP-43 expression, high doses of NGF suppress early GAP-43 production following peripheral axotomy and are associated with decreased nerve regeneration in animal models. ${ }^{92,135}$ This may be due to exogenous NGF delaying neuronal recognition of an injury state and the subsequent conversion to a neuronal re-growth state. ${ }^{92,135}$ Overall, relatively little work has been done to elucidate the roles of constitutive or elevated GAP-43 expression in response to corneal injury. 
Small proline-rich protein 1a (Sprr1A): A member of the small proline-rich protein (Sprr) family, Sprr1A expression has been observed in animal models of injured peripheral nerves, as well as in the cornea following surgical transection. ${ }^{42,202}$ Sprr1A expression is accompanied by elevated BDNF and GAP-43 levels in the injured cornea, suggesting a regenerative neurotrophic property. ${ }^{42}$ Sprr1a is not expressed during development or in naive adult nervous tissue. ${ }^{31}$ It is not normally present in sensory neurons, but its delayed de novo expression after peripheral nerve injury, as well as the fact that overexpression increases neurite outgrowth, suggest Sprr1a is a regeneration-specific protein. ${ }^{31,202}$ Sprr1A is robustly and significantly expressed during corneal nerve regeneration in vivo. ${ }^{42}$ Sprr1a has been localized in human corneal epithelium in the context of envelope proteins, but unlike other members of the Sprr family, its expression does not change in response to epithelial stress injury. ${ }^{215}$ Sprrlb, but not Sprrla, is a proposed biomarker for corneal epithelium squamous metaplasia and keratinization. ${ }^{126} \mathrm{Sprr} 1 \mathrm{a}$ is induced during epithelial differentiation in rat keratinocytes, and may contribute to the permeability barrier function of corneal epithelium. ${ }^{190}$ Given that corneal epithelial cells undergo continuous turnover, ${ }^{84}$ and the sensory endings in the corneal epithelium also undergo continual rearrangement, 85 it is possible that different family members of the small proline rich proteins may differentially regulate epithelial and nerve remodeling. The common properties of Sprrla with other cornified epithelium genes (e.g., upregulation of Sprr family genes with ultraviolet light stress) raise the possibility that peripheral axonal regeneration uses a shared gene program with epithelial differentiation. ${ }^{31}$ Therefore, epithelial innervation, differentiation, and permeability barrier function are interlinked processes.

$\beta$-tubulin III (Tubb3): Tubulins are structural proteins involved in nerve growth, and neurotrophins like NGF promote tubulin expression. ${ }^{70,152} \beta$-tubulin III (Tubb3) expression is significantly increased in the mouse cornea approximately 2 weeks after surgical transection and positively correlates with BDNF and Sprr1A expression. ${ }^{42}$ Tubb3 upregulation is associated with nerve regeneration in the injured peripheral nervous system, and loss of Tubb3 upregulation after peripheral nerve injury is associated with attenuated nerve regeneration in a diabetic animal model. ${ }^{229}$

\section{B4c. Inflammatory mediators}

T lymphocytes: In the murine cornea, a subset of helper T cells (IL-17+ $\gamma \delta \mathrm{T}$ cells) is pivotal in corneal nerve repair and regeneration. ${ }^{127}$ Loss of these $\mathrm{T}$ cells reduces the inflammatory response with $>50 \%$ decrease in nerve regeneration, likely due to loss of $\mathrm{T}$ cell-induced cytokine signaling and related reduction in VEGF. This suggests a pro-neural role for both these $\mathrm{T}$ cells and inflammation in general.

Leukemia inhibitory factor (LIF): Leukemia inhibitory factor (LIF) is a neuropoietic cytokine expressed in a variety of cell types, including inflammatory cells, epithelium, and corneal tissues. ${ }^{189}$ LIF enhances in vitro stem cell proliferation in human epithelial limbal cells, and is involved in pro-inflammatory signaling cascades. In the healthy murine cornea, LIF is expressed in vivo in epithelial cells, ${ }^{189}$ suggesting a role for corneal health maintenance and function as well as a potential reservoir for immediate chemoattractant 
signaling upon injury. In a LASIK rabbit model, following injury LIF accelerates corneal nerve regeneration. ${ }^{177}$

Interleukins 6, 17 (IL-6, 17): Interleukin-6 (IL-6), a neuropoietic cytokine involved in immunomodulation as well as neuronal survival and function, ${ }^{238}$ is synthesized in peripheral sensory neurons and corneal epithelium and promotes stromal inflammation, neuronal differentiation via the NGF Trk receptor, and neuronal survival with concurrent upregulation of NGF. ${ }^{204,205,238}$ IL-6 synthesis increases in pathological states; ${ }^{238}$ however, IL-6 has been implicated in pathologic chronic inflammation of keratoconus. ${ }^{124}$ Another cytokine involved in neurogenic inflammation is IL-17. In the murine cornea, injury (including surgical transection) is followed by accumulation of IL-17+ $\gamma \delta$ helper T cells and inflammatory cells that promote complete epithelial and near-complete nerve recovery. ${ }^{127}$ Loss of these helper T cells and/or IL-17 leads to a $>50 \%$ reduction in corneal nerve regeneration. ${ }^{127}$

\section{B4d. Hormonal regulators}

Thyroxine: Thyroxine increases NGF and augments nerve regeneration in the central and peripheral nervous systems, respectively. ${ }^{172,223}$ Little is known about thyroxine in the cornea. In the developing chick, exogenous thyroxine increases nerve elongation, possibly via increased actin cytoskeleton polymerization that is required for neuronal outgrowth. 46 In the human peripheral nervous system, thyroxine may signal through VEGF or EGFR to modulate neuronal migration and wound healing. ${ }^{40,55}$ Thyroid hormone receptor is present in all layers of the cornea, ${ }^{47}$ although the effects of thyroxine on corneal nerve regeneration are unknown.

Corticosteroids: Corticosteroids regulate inflammation and cell proliferation and can be synthesized by peripheral nerves. ${ }^{148}$ Neural roles for endogenous corticosteroids include changes in Schwann cell morphology and proliferation in the peripheral nervous system, serving as coactivators required for myelination. ${ }^{148}$ Little is known about the role of endogenous steroids in the cornea; however, the cornea has numerous steroid hormone receptors, and ocular tissues express mRNA for 5a-reductase, an enzyme required for metabolizing steroid hormones to biologically active molecules. ${ }^{81}$ For information regarding the role of exogenous corticosteroids, see the "Treatment methods" section of this review.

\section{B4e. Miscellaneous neuromodulators}

Pituitary adenylate cyclase-activating polypeptide (PACAP): Pituitary adenylate cyclaseactivating polypeptide (PACAP) acts as a neurotransmitter (a C fiber neuropeptide ${ }^{224}$ ) and has neuromodulating effects. PACAP induces corneal neurite outgrowth and accelerates the return of corneal sensitivity after surgical transection. ${ }^{76}$ PACAP responds to nitric oxide (NO) levels, and NO may activate ocular C fibers following injury. ${ }^{224}$ PACAP increases concomitantly with NO in response to inflammation. ${ }^{224}$ PACAP may prove to be a viable pro-neural factor once its role following injury in corneal nerves is elucidated. 
Collagen XVIII: Components of the extracellular matrix play pivotal roles in peripheral nervous system growth and regeneration. ${ }^{194}$ Collagen XVIII localizes to the basement membrane of corneal nerves, and is required for proper corneal nerve organization and appropriate regeneration after surgical transection. ${ }^{194}$ Re-growth of corneal nerves appears to occur with the laying down of new basement membrane, ${ }^{13}$ suggesting the importance of a healthy membrane and the presence of collagen XVIII in the regeneration process.

\section{CORNEAL NERVE DYSFUNCTION}

\section{C1. Corneal diseases causing nerve dysfunction}

Neurotrophic keratopathy can be caused by a variety of infectious agents, as well as congenital, ocular, and systemic diseases, pharmaceutical agents, trauma, and corneal dystrophies. ${ }^{226}$ Sensory nerves in the cornea deploy afferent stimulation signals to the brain, which then returns an efferent signal; for example, to the lacrimal gland via autonomic nerves to drive tear production and secretion. When the cornea is damaged, these neural circuits are disrupted. Corneal nerve damage leads to neurotrophic keratopathy either directly (via loss of supportive neuropeptides) or indirectly (via disruption of neural circuits resulting in, for example, dry eye). Thus, corneal nerve impairment is responsible for epithelial defects, ulcerations, corneal perforations, and reduced function of corneolimbal stem cells ${ }^{33,217}$ (Figure 5). Late-stage neurotrophic keratitis patients are often asymptomatic because of significantly decreased corneal sensation. ${ }^{226}$ We will now elucidate the interdependence between corneal nerves and epithelium and highlight the complicated role of inflammation in the pathophysiology of neurotrophic keratopathies.

Infection negatively affects corneal tissues and corneal nerves. Neurotrophic keratitis can be caused by herpes viruses [herpes-simplex virus type 1 (HSV 1) and varicella-zoster virus (VZV)], Mycobacterium leprae, Acanthamoeba, and fungal infections. Acanthamoeba and fungal keratitis more profoundly impact corneal nerves. ${ }^{116}$ In these infections, with the exception of leprosy, the subbasal plexus exhibits at least a 2- to 3-fold reduction in the number of nerve fiber bundles, total nerve number, and branching, along with increased tortuosity. ${ }^{83,116}$ Similar changes are seen in contralateral, uninfected eyes. ${ }^{83}$ Interestingly, in both the infected and uninfected eyes of HSV1 patients, subbasal plexus alterations directly correlate with corneal hypoesthesia related to disease duration and number of recurrences, ${ }^{83}$ while Acanthamoeba keratitis patients often present with significant pain, possibly neuropathic in nature. ${ }^{116}$ The location of corneal nerves within the layers of the cornea and the type of herpetic keratitis determine the extent of corneal nerve changes in response to herpetic infection. The subepithelial plexus exhibits destructive changes in epithelial and stromal HSV keratitis, but appears preserved in clinical endothelial keratitis. ${ }^{161}$

Leprosy is associated with changes in stromal nerve density, irregularities in epithelial nerves, and corneal nerve thickening, tortuosity, and beading, accompanied by hypoesthesia. ${ }^{237}$ Inflammatory mediators have conflicting roles in infectious neurotrophic keratopathy. Activation of latent VZV causes inflammatory destruction of corneal nerves, ${ }^{196}$ whereas inflammation-related neuropeptides can be beneficial in reducing herpetic keratopathies. Trigeminal and corneal sympathetic nervous system activity and 
increased interferon- $\gamma$ levels ward off infection in mice, ${ }^{212}$ thus preserving corneal nerves. Combination treatment with SP and IGF-1 completely resolves epithelial defects in neurotrophic keratopathy patients, though SP may worsen microbial keratitis by promoting excess inflammation. ${ }^{72,212,230}$ Non-infectious disease processes, both corneal and systemic, also negatively affect corneal nerves.

Keratoconus, bullous keratopathy (e.g., in the setting of Fuchs' dystrophy), and atopic keratoconjunctivitis (AKC) are associated with inflammation of the ocular surface and are accompanied by pathological alterations of corneal tissues and loss of corneal sensitivity. $3,5,95,124,136,170$ Nerves of the subbasal plexus exhibit significant loss of density, branching, and diameter, with increased tortuosity in conjunction with the stromal nerve changes of localized thickening, twisting, or looping. ${ }^{3,5,95,136,170}$ In keratoconus, subbasal nerves may also be thickened. ${ }^{170}$ Thickened subbasal and stromal nerves appear approximately 1.5 - to 2 -fold wider than those of healthy controls, which may be due to keratocyte "wrapping" of the nerves rather than genuine hypertrophy. ${ }^{136,170}$ Subbasal nerves in the keratoconic corneal apex exhibit altered architecture, consisting of horizontal and oblique orientations of closed loop nerve fibers and abrupt terminations instead of the whorl-like arrangement of the healthy cornea. ${ }^{182}$ Epithelial nerves display density loss in the subepithelial plexus. ${ }^{136}$ Corneal nerves have been implicated in keratoconus pathophysiology through nerve damage (such as a cranial nerve $\mathrm{V}$ palsy), proteolytic enzyme activity (cathepsin B and G) in keratocytes and nerve terminals associated with thickened nerves, or loss of neurotrophic signaling (NGF and its receptors). ${ }^{35,119,193}$ It is unclear if these changes are underlying etiology or merely a result of the disease. Noninfectious systemic diseases, including autoimmune diseases and systemic polyneuropathies, have similar detrimental effects on corneal nerves.

Autoimmune diseases negatively affect corneal nerve parameters including density, tortuosity, beading, and function. Graves' disease, or any significant thyroid dysfunction, may be accompanied by dysthyroid ophthalmopathy with signs and symptoms of corneal nerve dysfunction. ${ }^{14}$ Decreased serum NGF is associated with the occurrence of Graves' ophthalmopathy, and there are fewer subbasal nerve fibers and increased tortuosity and beading. ${ }^{155,220}$ Nerve function is reduced, which may be due to neurotrophic factor deprivation from loss of corneal epithelium integrity. ${ }^{89,220}$ Epithelial defects have been reported in cases of severe Graves' ophthalmopathy. ${ }^{89}$ These defects may worsen with corticosteroid therapy, likely due in part to suppression of proneural cytokines. ${ }^{89,220}$ The autoimmune Sjögren's syndrome (SS) exemplifies the relationship among corneal nerves, tear secretion, and epithelial integrity. Corneal nerve damage, for example from refractive surgery, may lead to tear hyposecretion. The resultant dry eye and dry eye epitheliopathy further damages corneal nerves, perpetuating the dry eye disease state and predisposing to neurotrophic keratopathy. In fact, SS is associated with compromised nerve function, thickened nerves, increased subbasal nerve tortuosity, and beading. ${ }^{24,216}$ Disagreement exists (perhaps due to different testing modalities) over changes in subbasal nerve density and beading and whether there is increased or decreased corneal sensitivity. ${ }^{24,216}$ Inflammation in dry eye disease like SS may be a response to efferent nerve stimulation in the cornea that results in the release of neuropeptides such as CGRP and SP. 203 Inflammation may be beneficial for nerve regeneration. ${ }^{127}$ Activated keratocytes, induced 
by pro-inflammatory cytokines, are capable of secreting NGF, which may improve corneal sensitivity and restore corneal integrity, possibly via ACh and SP production with concurrent sympathetic nervous system modulation. ${ }^{24,33}$ Nerve growth cones and sprouts have been observed in conjunction with keratocyte activation. ${ }^{24,216}$ In animal studies, epithelial damage is exacerbated by sympathetic innervation and ameliorated by CGRP, SP, $\mathrm{ACh}$, and IGF-1. ${ }^{33}$ It is unclear if corneal nerve damage occurs as a primary component of these autoimmune diseases, or whether it is secondary to other orbital pathophysiology. Other, systemic polyneuropathies exhibit similar negative impacts on corneal nerves.

Systemic polyneuropathies that can lead to neurotrophic corneal ulceration include peripheral diabetic neuropathy (PDN), amyloidosis, sarcoidosis, vitamin B12 deficiency, and alcoholism. The majority of corneal symptoms experienced by polyneuropathy patients like diabetics are the result of damage of the cornea's small $\mathrm{A} \delta$ and $\mathrm{C}$ nerve fibers that can lead to neurotrophic keratopathy. ${ }^{86,94}$ Central corneal epithelial nerve density is markedly decreased. ${ }^{86}$ The subbasal plexus exhibits both reduced density and branching with increased tortuosity and nerve thickening. ${ }^{153}$ These findings positively correlate to decreased corneal sensitivity and systemic disease severity. ${ }^{94}$ Stromal nerves appear thickened and may have increased looping or curving of nerve fibers, and diabetic corneas exhibit aberrant nerve regeneration. ${ }^{86} \mathrm{~A} \delta$ mechanoreceptors may be affected prior to and differently from polymodal C fiber nociceptors. ${ }^{160} \mathrm{NGF}$ is elevated in diabetic patients, though levels of NGF and its receptors decrease in proportion to disease severity. ${ }^{110}$ PDN can lead to corneal epithelial disease even before the underlying diabetes has been diagnosed, ${ }^{137}$ and neurotrophic keratopathy should be considered when a known diabetic develops corneal epithelial disease.

Hereditary sensory and autonomic neuropathies (HSAN, types IV and V) exhibit compromised nerve function with corneal alacrima and analgesia, and may even lead to neurotrophic ulceration and corneal opacities. ${ }^{151}$ In the cornea, there is central loss of A $\delta$ fibers and impairment of the remaining $\mathrm{A} \delta$ and $\mathrm{C}$ fibers with a reduction in subbasal nerve bundles and decrease in corneal sensation. ${ }^{151} \mathrm{HSAN}$ IV and V display mutations in NGF and its Trk receptor, resulting in impaired nociceptor development and function. ${ }^{151}$ Congenital aniridia is often accompanied by corneal changes, and $80 \%$ of patients display keratopathy (aniridia-related keratopathy [ARK]) that correlates with a loss in corneal sensitivity. ${ }^{59}$ ARK also correlates with, and may be brought on by, intraocular surgery. ${ }^{59}$ ARK may be a type of neurotrophic keratitis due to a Pax6 abnormality of corneolimbal stem cells and aberrant nerve projection, though a Pax6 animal model suggests the keratopathy is not neurotrophic in nature. ${ }^{59,123}$ Another rare disease that involves corneal nerve dysfunction is ocular-auriculo-vertebral dysplasia (OAV or Goldenhar syndrome). Caused by a trigeminal nerve malformation, patients may present with corneal hypoesthesia and keratopathy. ${ }^{221}$ Multiple endocrine neoplasia (MEN) 2A and B are associated with corneal nerve thickening due to a putative genetic alteration and axon and Schwann cell abundance, respectively. ${ }^{103,206}$ In MEN2B, keratoconjunctivitis sicca and meibomian gland dysfunction may accompany nerve thickening, though epithelial changes may be a result of lid and meibomian gland malfunction and not corneal nerve dysfunction. ${ }^{103}$ In other polyneuropathies, such as small fiber neuropathies of autoimmune, pharmacologic, or 
idiopathic origin, patients also demonstrate reduced sensitivity, nerve fiber density, branching, and length, with a concomitant increase in tortuosity. ${ }^{211}$

Pharmacological agents may also lead to keratitis and compromise corneal nerves. Topical analgesics, notably the non-steroidal anti-inflammatory drug (NSAID) diclofenac, can delay corneal wound healing and result in epithelial breakdown and corneal melting. ${ }^{77,227}$ Direct damage from anesthetics, such as proparacaine, retards healing and causes epithelial defects. ${ }^{187,227}$ The epithelial damage negatively affects corneal nerves, which elicits pain. The pain prompts further anesthetic use, which exacerbates the initial epithelial defect. Topical morphine does not appear to be toxic in experimental corneal abrasions in rabbits. ${ }^{187}$ Analgesic use is warranted for corneal nerve injuries from many causes, including chemical and physical trauma.

Corneal nerves can be injured by chemical and physical trauma. Exposure to chemical agents, such as carbon disulfide and hydrogen sulfide, reduces corneal sensitivity and can irritate the cornea at high concentrations. ${ }^{141}$ Exposure to mustard gas [bis- (2-chloroethyl) sulfide] results in corneal epithelial ulceration and destruction. ${ }^{100}$ Patients with chronic mustard gas keratopathy exhibit thickened midstromal nerves and loss of the subbasal nerve plexus; however, this latter finding could be explained by concordant dry eye. ${ }^{100} \mathrm{In}$ addition to chemical factors, physical trauma to corneal nerves ranges from accidental abrasions to planned surgical transection of corneal nerves. As with corneal nerve damage by previously discussed modalities, traumatic injury to corneal nerves can lead to altered function and neurotrophic keratitis.

\section{C2. Corneal surgeries causing nerve dysfunction}

C2a. Corneal nerve transection in refractive vision correction-In 2007, the American Academy of Ophthalmology estimated 42.5 million patients in the United States over the age of 40 years had refractive disorders. ${ }^{10}$ Laser in situ keratomileusis (LASIK) is the most common surgical procedure for vision correction, with 1.5 million procedures performed in the United States in 2005. ${ }^{10}$ Laser sub-epithelial keratomileusis (LASEK) and photorefractive keratectomy (PRK) are alternatives. Comparing the effects of these refractive surgeries on corneal nerves is difficult because of the variability among studies regarding the type of surgery, depth of excision, and extent of nerve damage already present or inflicted. ${ }^{21}$ In PRK and LASEK, superficial and subbasal nerves are ablated, whereas the majority of stromal nerves remain intact. In PRK, subbasal nerves regenerate from stromal nerves to near pre-operative density by 3 years ${ }^{63,180}$ and restore corneal sensitivity after an average of approximately 2 months. ${ }^{34,62,114,142,168,181}$ LASEK demonstrates a recovery of corneal sensitivity to the pre-operative state within approximately 3 months, ${ }^{54}$ though a recent review suggests anatomical nerve recovery may take 6 months or more. ${ }^{180} \mathrm{In}$ contrast, during LASIK procedures, stromal nerves through the stromal bed are transected. ${ }^{21,63,181}$ Post-LASIK, the subbasal plexus density decreases more than $80 \% .{ }^{57,154}$ Nerve regrowth is observed in the central cornea by 6 months post-procedure, though it may be 5 years before nerve densities achieve pre-operative levels. ${ }^{54,63,154,180}$ (refer to Table 3 for a comparison of subbasal nerve changes after refractive surgeries) Nerve regrowth may not mimic the native state. ${ }^{180} \mathrm{In}$ a murine model undergoing lamellar 
corneal dissection, regenerating nerves in the central stromal were comprised of nonmyelinated nociceptive fibers as well as myelinated fibers. ${ }^{165} \mathrm{In}$ the pre-operative native state, myelinated fibers are limited to the peripheral corneal stroma. Discrepancies exist regarding subepithelial plexus regrowth as well after refractive surgery, 107 although it is generally accepted that central regrowth is present by 6 months post-operatively and corneal sensitivity returns approximately 3 to 9 months post-LASIK and arguably does not depend on long-term nerve abnormalities. ${ }^{54,63,154,180,191}$ Depth of ablation is debatably a significant factor in time to recovery of corneal sensitivity. ${ }^{25,167}$ Figure 6 illustrates postLASIK changes in the subbasal plexus. LASEK appears to have a more favorable recovery profile, whereas LASIK may be associated with LASIK-induced neurotrophic epitheliopathy (LINE), dry eye, and neuropathic pain. ${ }^{21,122,191}$

Transection of corneal nerves in LASIK disrupts the regulatory loops of neurotrophins, growth factors, and cytokines across the cornea, nervous system, and lacrimal gland. ${ }^{191}$ Figure 7 demonstrates superficial punctate keratitis associated with LINE. LINE improves with nerve healing 6 months post-procedure, but dry eye and neuropathic pain may become chronic. ${ }^{21,57}$ One study reports that nearly $50 \%$ of LASIK patients experience dry eye 6 months post-operatively. ${ }^{191}$ Damaged nerves exhibit altered ion channel conductivity resulting in aberrant hypersensitivity firing and dysesthesias. ${ }^{21}$ The extent of side effects reportedly depend upon flap hinge width, depth, and location. ${ }^{157}$ Increased incidence of LASIK-induced dry eye has been shown in flaps created with a microkeratome compared to a femtosecond laser, ${ }^{195}$ though reinnervation rates remain similar. ${ }^{184}$ While recent studies find no effect of hinge position on nerve recovery, ${ }^{96}$ earlier reports suggested that corneal flaps with superior hinges have a greater risk of dry eye and reduced corneal sensation compared to nasal hinged flaps. ${ }^{57}$ The performance of a horizontal flap is supported by the model of corneal innervation proposing that the long ciliary nerves enter the cornea at the 3and 9-o'clock positions, suggesting that there is greater susceptibility to corneal nerve damage with vertically than horizontally hinged flaps; ${ }^{57}$ however, He et al. ${ }^{87}$ have recently reported that corneal nerves enter the stroma in a radial pattern, and the distributions of stromal nerves and epithelial nerve are similar in each corneal quadrant; thus providing direct anatomical evidence that the position of the corneal flap is irrelevant.

C2b. Reinnervation following corneal transplant surgery-Corneal allograft procedures include penetrating keratoplasty (PK), lamellar keratoplasty (LK), deep anterior lamellar keratoplasty (DALK), Descemet stripping automated endothelial keratoplasty (DSAEK), and epikeratophakia. PK involves full thickness trephination of the host cornea to prepare the bed for transplantation. Trephination transects the stromal nerves circumferentially. ${ }^{7}$ Following PK, subbasal and epithelial re-innervation of the donor graft occurs to some degree, however, stromal innervation is quite limited. In a recent review, ${ }^{7}$ Al-Aqaba et al. note that subbasal nerve density does not recover by 30 years after PK, and significant alterations to the subbasal nerve plexus are apparent even 40 years later. In full thickness corneal grafts, the majority of regenerated nerves in the donor tissue are a continuation of host subbasal nerves, which cross the graft-host junction to innervate the peripheral part of the grafts. Stromal nerve trunks from the host tissue may stop at the edge of the graft and in some instances are completely absent in the donor tissue. When stromal 
nerves do invade the donor tissue, they frequently innervate only the peripheral areas.

Regenerated stromal nerves do not contribute to the epithelial innervation. In normal cornea, the subbasal nerves arise from the stromal nerves and there are numerous connections between them. Following PK, these normal links between the subbasal and stromal nerves are absent in donor tissue. ${ }^{7}$ Recovery of corneal sensation is of some debate, returning by 1 year or reduced for decades after PK, and does not seem to correspond to the degree of anatomic re-innervation. ${ }^{7,53}$ Epithelial and subbasal innervation in the donor graft is generally necessary for some degree of corneal sensation restoration. ${ }^{7}$ In DALK, a full thickness donor cornea (with Descemet membrane and endothelium removed) is transplanted over host Descemet membrane and endothelium. The recovery of corneal sensitivity in the graft following PK or DALK is similar, with one comparative study obtaining good corneal sensitivity by 2 years after surgery. ${ }^{41}$ This is because in both procedures, all stromal nerve trunks are transected in the process of preparing the host bed. DSAEK is a technique of corneal transplantation that allows for selective replacement of diseased endothelium and Descemet membrane. In contrast to PK and DALK, DSAEK does not cause corneal hypesthesia. ${ }^{115}$ This is not surprising because corneal nerves do not innervate Descemet membrane or the corneal endothelium. In epikeratophakia, epithelial nerves are lost in conjunction with long-term reduction in subbasal nerve density. ${ }^{19,68}$

\section{C2c. Corneal nerves following collagen crosslinking (CXL)-Riboflavin UVA-} induced corneal collagen crosslinking $(\mathrm{CXL})$ is a relatively new treatment for progressive keratoconus and post-LASIK corneal ectasia that may reduce the need for keratoplasty. ${ }^{144}$ CXL combines riboflavin treatment with UVA irradiation to promote connections, or crosslinking, among collagen fibers to strengthen the disease-weakened cornea. CXL can be performed either transepithelial (without epithelial removal) or after de-epithelialization (with epithelial removal). CXL after epithelial removal results in loss of subepithelial plexus and anterior-midstromal nerves. ${ }^{144}$ By 6 months post-CXL, sensitivity is restored, and nerve fiber regeneration is nearly complete. ${ }^{144}$ In contrast, following transepithelial CXL, subepithelial and stromal nerve plexi remain intact. ${ }^{39} \mathrm{CXL}$ postoperative pain is intense and worse than pain after PRK, particularly during the first 3 days after surgery, and necessitates an aggressive postoperative pain control regimen. ${ }^{78}$ The pain is neuropathic in nature and mitigated by age. ${ }^{78}$ Re-epithelialization is accompanied by a significant decrease in both pain and the need for analgesia on each consecutive day. ${ }^{78}$ One of the sources of intense pain might be the destructive effect that CXL has on the subbasal nerve plexus while keeping the majority of stromal nerves intact within a postoperative milieu. ${ }^{78}$

C2d. Recombinant human collagen (RHC) corneal substitutes-Recombinant human collagen (RHC) corneal substitutes are being tested as therapeutic corneal replacements. RHC implants have minimal inflammation and/or neovascularization and exhibit partial regeneration of subbasal nerves as well as a return of corneal sensitivity. ${ }^{67}$ 


\section{THE LINK BETWEEN INFLAMMATION AND NERVE REGENERATION PATHWAYS}

Inflammation plays a key role in peripheral nerve regeneration. ${ }^{26}$ Corneal nerve regeneration and inflammation pathways appear to be intertwined. (Table 4) Corneal nerve regeneration is enhanced by a $\gamma \delta \mathrm{T}$ cell-dependent inflammatory cascade that involves IL-17, neutrophils, platelets, and VEGF-A. ${ }^{127}$ A strong and significant correlation has been reported between increased numbers of dendritic-shaped cells of the central cornea and decreased subbasal corneal nerves, suggesting a potential interaction of the immune and nervous systems during corneal infections. ${ }^{52}$ Loss of the subbasal nerve plexus occurs in non-infectious inflammatory eye diseases as well. ${ }^{24,219}$ In addition, we reported previously that immunomodulation with cyclosporine eye drops in an animal model reduces cytokine expression in the cornea and retards regenerative sprouting from transected corneal stromal nerve trunks. ${ }^{163}$ Our data also revealed that topical benzalkonium application to the eye increases corneal inflammation and induces neurotoxocity. ${ }^{197}$ These findings suggest the presence of molecular regulators in the cornea that straddle the immune and nervous systems.

Taken together, these studies suggest that some degree of inflammation (inflammatory cells, molecules, or chemokines) promotes corneal nerve regeneration, whereas excessive inflammation may lead to loss of corneal innervation and subsequent neurotrophic keratopathy. The nervous and immune systems communicate biochemically. Neurons, including nociceptors, express functional receptors for cytokines, whereas cells of the immune system may recognize, and are modulated by, neuropeptides (reviewed by Li et al. ${ }^{125}$ ). In fact, neural signaling with SP and/or VIP promotes resistance to infection by stimulating immune system effectors (reviewed by Cruzat et al. ${ }^{52}$ ). We reported that one molecule, Sema7A, is shared by the nervous and immune systems and links nerve regeneration and inflammation in the murine cornea. ${ }^{164}$ In the peripheral nervous system, Sema7A enhances axonal outgrowth. In the immune system, Sema7A is expressed in activated $\mathrm{T}$ cells and plays a role in T cell-mediated inflammation. In the cornea, Sema7A is constitutively expressed in the epithelium and stroma. Following corneal wounding, Sema7A stimulates nerve regeneration in association with inflammatory cell influx. From the narrow perspective of nerve regeneration, the most direct practical implication of these studies is that avoiding long-duration immunomodulation or anti-inflammatory treatment may benefit corneal reinnervation if postoperative healing is uncomplicated.

\section{E. EVIDENCE-BASED TREATMENT OF NEUROTROPHIC CORNEAL DISEASE}

Corneal nerves have complex interactions with resident cells (limbal stem cells, epithelium, and antigen-presenting cells) as well as bone marrow-derived inflammatory cells that migrate into the cornea. Corneal nerve dysfunction from injury or disease perturbs these interactions and leads to neurotrophic keratitis, characterized by reduced corneal sensation, epithelial defects, and corneal scarring. The pathways controlling corneal nerve regeneration molecularly link with pathways that control corneal epithelium differentiation as well as its 
permeability barrier function. Furthermore, corneal nerves are essential for maintaining limbal stem cell homeostasis and function. ${ }^{217}$ Corneal nerve regeneration is enhanced by the presence of some degree of concomitant inflammation.

The therapeutic strategy to treat neurotrophic keratitis must consider the interactions of nerve regeneration and inflammatory pathways. In general, patients should discontinue use of all preserved eye drops. At least one common preservative, benzalkonium chloride, increases corneal inflammation and additionally has direct neurotoxicity. ${ }^{197}$ Topical corticosteroid and cyclosporine eye drops should also be avoided, as they can excessively retard inflammation and some inflammation appears facilitative of nerve regeneration. ${ }^{121,125,127,163}$ Corneal nerve regeneration can be stimulated by topical application of platelet-rich plasma (PRP) because platelets contain neurotrophic factors like VEGF and Sema7A. ${ }^{73,74}$ Silicone hydrogel soft contact lenses can be used as a bandage, and non-preserved artificial tears may be used for lubrication to promote healing. ${ }^{79,143,197}$ Oral minocycline may be used for neuroprotection. ${ }^{225}$ Treatment for refractory neurotrophic keratitis may include the ProKera amniotic membrane contact "lens," amniotic membrane transplantation, and/or tarsorrhaphy. Additional treatment includes topical NGF to promote corneal nerve regeneration. ${ }^{135}$ Taken together, the data support a multipronged approach to treat neurotrophic keratitis. The available therapeutic interventions are detailed individually below.

\section{E1. Neuro-regenerative}

\section{E1a. Blood component-based therapy}

E1a1. Serum eye drops: Autologous serum eye drops contain a variety of factors, including epidermal growth factor (EGF), TGF- $\beta$, vitamin A, SP, IGF-1, and NGF, that are proepithelial and pro-neural. ${ }^{232}$ Autologous serum eye drops effectively treat some cases of neurotrophic keratitis, as well as promote corneal epithelial healing in other ocular disorders such as dry eye. ${ }^{232}$ Tissue healing is accompanied by a return of corneal sensitivity. ${ }^{143}$ To prepare serum eye drops, blood samples are collected, clotted, and centrifuged before being diluted with balanced salt solution (BSS) or sterile saline. Therapeutic concentrations range from $20 \%$ to $100 \%$ autologous serum. In practice, preparations can be dispensed in $5-\mathrm{ml}$ bottles to be stored at $-20^{\circ} \mathrm{C}$, although storage at $-70^{\circ} \mathrm{C}$ is also recommended. When in use, the unused portion is stored at $4^{\circ} \mathrm{C}$, and opened bottles should be discarded after 16 hours. ${ }^{131}$ Appropriate preparation and serum concentration will optimize treatment of neurotrophic keratopathy with autologous serum eye drops. Liu et al. ${ }^{131}$ demonstrated that serum dilution in BSS promotes epithelial cell proliferation better than serum dilution in saline, as does centrifugation at higher speeds, (e.g., 3,000 $\times g$ ). Prolonged clotting times ( 120 minutes) enhance cell migration and differentiation. These improvements are thought to result from increased release of epithelial and neurotrophic factors from serum components. ${ }^{131}$ One study reported that dry eye disease and some neurotrophic keratopathies with epithelial defects were successfully treated with $20 \%$ autologous serum eye drops in sterile saline. ${ }^{143}$ Use of 50\% serum eye drops diluted in sodium hyaluronate or balanced salt solution treats a similarly high percentage of epithelial defects, and patients enjoy the increased viscosity, suggesting that a 50\% dilution of autologous serum eye drops should be the first-line treatment for neurotrophic keratopathy. ${ }^{43,105}$ Autologous serum eye 
drops are similar to umbilical cord serum eye drops (see below) because both improve recurrent epithelial erosions and promote complete epithelial healing in dry eye and non-dry eye keratopathies. ${ }^{231}$

E1a2. Umbilical cord serum eye drops: Like autologous serum, umbilical cord serum eye drops contain growth factors like EGF, vitamin A, TGF- $\beta$, SP, IGF-1, and NGF. They are used in the successful treatment of recurrent corneal erosion, neurotrophic keratitis, and dry eye syndrome. ${ }^{232}$ Umbilical cord serum generally appears more efficient in epitheliopathy symptom relief and healing time compared to autologous serum, ${ }^{231}$ likely because of the higher levels of EGF, TGF- $\beta$, SP, and NGF in umbilical cord serum. ${ }^{231}$ In addition, this is likely why a $20 \%$ dilution of umbilical cord serum eye drops successfully treats persistent neurotrophic keratitis refractory to conventional treatment. ${ }^{232}$

E1a3. Platelet-rich plasma (PRP): Platelets contain many bioactive compounds that play a role in inflammation and wound healing. ${ }^{74}$ These include platelet-derived growth factor (PDGF), TGF- $\beta$, VEGF, Sema7A, cytokines, and active metabolites. ${ }^{73,74}$ Platelet rich plasma (PRP) assists in cranial nerve regeneration in experimental models, ${ }^{69}$ and platelets are associated with murine corneal nerve regeneration. ${ }^{127}$ PRP successfully treats symptomatic dry eye, with a decrease in inflammation and fluorescein staining. ${ }^{8}$ Because it contains VEGF and Sema7A, two potent neurotrophic factors, PRP is theoretically a more powerful therapy than serum to treat neurotrophic keratitis. There are commercially available methods to produce PRP, though clinicians may also generate PRP in the clinic. Blood is collected and anticoagulated with citrate, followed by centrifugation to separate the PRP. Aspirin and NSAIDs cause permanent platelet dysfunction, and at least 1 week is required for megakaryocyte precursors to replenish the platelet population. Therefore, clinicians must ensure patients have discontinued aspirin or NSAID for at least 1 week prior to drawing blood for PRP.

E1b. Neurotrophic factors-NGF is responsible for axonal elongation and branching stimulation in chick explants. ${ }^{135}$ Exogenous NGF reverses damage to peripheral nerves and completely heals corneal epithelial defects such as those observed in neurotrophic keratitis. ${ }^{9}$ NGF eye drops improve corneal sensitivity and promote corneal epithelial healing in patients with moderate and severe neurotrophic keratitis. ${ }^{32}$ Topical application of NGF to the cornea has been reported to be safe and efficacious for treating epithelial defects in patients with congenital corneal anesthesia. ${ }^{209} \mathrm{NGF}$, in combination with neuromediators, may potentiate regenerative effects. NGF and decosahexanoic acid (DHA), an omega-3 fatty acid postulated to have neuroprotective activity, exhibit enhanced nerve and epithelial regeneration in animal experiments. ${ }^{66}$ DHA may aid recovery of corneal sensitivity recovers to near-normal levels, perhaps mediated via the DHA-derived lipid mediator neuroprotectin D1 (NPD1), a docosanoid with neuroprotective actions. ${ }^{49}$

VEGF is another growth factor with positive effects on corneal nerve healing. VEGF appears necessary for corneal nerve regeneration following wounding. Blocking VEGF-A results in reduced murine subbasal neuron regeneration by nearly $80 \%$ of total corneal nerves, and exogenous VEGF doubles regenerating nerve density. ${ }^{127,236}$ The VEGF antibody bevacizumab binds VEGF and inhibits inflammation-induced angiogenesis and 
lymphangiogenesis in corneal experimental models. ${ }^{236}$ The effects of bevacizumab treatment on human corneal nerves remain unknown.

\section{E2. Ensconcing}

E2a. Contact lenses-Contact lenses can be used in a protective manner for neurotrophic keratopathy. Choi et al. successfully treated persistent epithelial defects of neurotrophic keratopathy with a combination of silicone hydrogel lenses with 50\% autologous serum eye drops. ${ }^{43}$ Silicone hydrogel lenses maintain hydration and have increased oxygen transmissibility, which lessens hypoxic conditions. ${ }^{43}$ Silicon hydrogel contact lens materials include senofilcon A (Acuvue Oasys ${ }^{\circledR}$ ) and narafilcon B (Acuvue TruEye ${ }^{\circledR}$ ). A special contact lens, ProKera ${ }^{\circledR}$ (Bio-Tissue, Inc., Miami, FL) is designed specifically to promote corneal healing. The ProKera lens, comprised of amniotic membrane stretched within a polycarbonate ring conformer, speeds healing and improves visual outcome in patients with corneal wounding such as neurotrophic keratitis, likely via its delivery of amniotic membrane growth factors. ${ }^{176}$ Prosthetic replacement of the ocular surface ecosystem (PROSE, Boston Foundation for Sight), is a scleral contact lens-based strategy that is another effective alternative for recalcitrant neurotrophic corneal disease. ${ }^{130}$

E2b. Amniotic membrane transplant (AMT)—Preserved human amniotic membrane can be transplanted as a basement membrane substitute. Indications for AMT include corneal ulceration, persistent epithelial defects, band keratopathy, limbal stem cell deficiencies, acute herpetic keratitis, and Stevens-Johnson syndrome. AMT promotes ocular epithelialization, most likely because of intrinsic EGF, keratocyte growth factor, and neurotrophins. ${ }^{108,149}$

E2c. Tarsorrhaphy-Tarsorrhaphy facilitates healing of recalcitrant epithelial defects in neurotrophic keratitis. By decreasing the width of the palpebral fissure, tarsorrhaphy decreases the evaporation rate of tears. Tarsorrhaphy also minimizes the traumatic effect of lid movement over a healing epithelial defect. ${ }^{50}$ Tarsorrhaphy is successful in healing more than $90 \%$ of persistent epithelial defects from neurotrophic ulcers that are refractory to conventional therapies. $50,75,97$

\section{E3. Anti-inflammatory}

E3a. Cyclosporine A-Cyclosporine A (CSA), an anti-inflammatory immunosuppressant drug that is potentially neuroprotective, ${ }^{58}$ resolves inflammatory T-cell infiltrates ${ }^{58,163}$ and is believed to increase tear production by reducing ocular inflammation of dry eye disease. ${ }^{58} \mathrm{CSA}$ also promotes lymphocyte apoptosis and inhibits epithelial apoptosis. ${ }^{58}$ CSA use in dry eye patients results in improved patient comfort and tear production and decreased pathologic staining in corneal epithelium. ${ }^{58}$ Because the goal of treatment is similar in patients with neurotrophic keratitis and dry eye disease, (that is, improved comfort, reduced photophobia, and decreased corneal staining), it seems logical to use CSA to treat neurotrophic keratitis; however, in the neurotrophic keratitis setting, the direct effect of CSA on corneal nerves may be detrimental, retarding nerve fiber regeneration due to loss of pro-neural IL- 6 signaling and IL-17+ $\gamma \delta$ helper T cells, as well as decreased transcription factors [NFATC1 and MAPK14 (p38)] and neurotrophins (BDNF and NT 4/5). ${ }^{58,163}$ A 
concomitant increase in c-fos and pro-neural GAP43 may explain why some neural regeneration still occurs with CSA treatment. ${ }^{163}$

Ocular surface surgeries may sever corneal nerves and interrupt a neural feedback loop between the ocular surface and lacrimal glands. Therefore, to reduce the occurrence of dry eye symptoms after LASIK and cataract surgery, a preoperative and postoperative topical CSA regimen is recommended, particularly in patients who have pre-existing dry eyes or who are at risk of developing dry eye. ${ }^{58}$ Although topical CSA use in the context of dry eye disease is beneficial, its benefits in the context of established neurotrophic keratitis are unknown. Until clinical data become available, the current data from experimental studies support limiting CSA use in neurotrophic keratitis.

E3b. Corticosteroids-The effects of corticosteroids on corneal nerves are mixed. Steroids are associated with ocular surface epithelial toxicity and delayed epithelial healing; ${ }^{145}$ however, post-wounding, steroids may speed epithelial recovery and reduce pain by inhibiting prostaglandins and sympathetic nerve sprouting (identified in animal models), ${ }^{33,125}$ improve corneal nerve health in diseases such as autoimmune neuropathy, and help reverse the neuropathic findings of abnormal nerve thickening and tortuosity. ${ }^{117}$ Corticosteroids, however, suppress pro-neural NGF and inflammatory cytokines such as IL-6, reduce T cell-mediated inflammation, and inhibit sympathetic nerve sprouting in response to injury in both animal models and human cornea. ${ }^{121,125}$ In patients with dry eye disease, corticosteroids result in epithelial healing and subjective improvement of dry eye symptoms, although measures of corneal nerve function like tear film breakup time and Schirmer tear tests do not significantly improve. ${ }^{121}$ Corticosteroids exert their effects in a dose- or time-dependent manner, ${ }^{145}$ which may explain the seemingly conflicting results in nerves following wounding.

Topical application of corticosteroid eye drops reduces corneal inflammation but can produce epithelial toxicity. Because corneal epithelial cells, as well as sensory nerve endings, undergo continuous turnover ${ }^{84,85}$ and share molecular mechanisms of regeneration, delayed epithelial healing from steroid use may concomitantly cause delayed nerve regeneration. In animal studies, corticosteroids retard corneal epithelial regeneration, inhibit stromal healing, and even cause superficial epithelial necrosis. ${ }^{145}$ Therefore, topical corticosteroid eye drop use should be minimized in neurotrophic keratitis.

E3c. Corneal analgesics-Several pharmacological mediators are used for corneal analgesia, including NSAIDs, resiniferatoxin (RTX), opioids, and dilute anesthetics. NSAIDs reduce pain associated with corneal injury, such as occurs after refractive surgery or inflammatory processes. ${ }^{2}$ NSAIDs, particularly diclofenac, inhibit inflammatory mediators in a nociceptor-specific manner, resulting in decreased responsiveness of corneal A $\delta$ and $C$ polymodal nociceptors to pain, chemical, mechanical, and thermal stimuli. ${ }^{2}$ NSAIDs reduce post-surgical hypersensitivity, but some debate exists regarding compromise of the neurotrophic signaling required for nerve growth. ${ }^{27,77}$ Significant adverse effects have been reported, including corneal perforation or "melting." 80 These harmful effects may be the result of inhibition of beneficial cyclooxygenase products or of analgesia that prevents a protective response to external traumatic forces. Therefore, the use 
of topical NSAIDs should be avoided in neurotrophic keratitis. Whereas NSAIDs rely on blocking inflammatory mediators, other analgesics target TRPV1, a signaling calciumpermeable channel highly expressed in nociceptive neurons. ${ }^{17,159}$ RTX is a TRPV1 agonist. RTX binding leads to calcium influx and subsequent dose-dependent cytotoxicity, resulting in ablation of nociceptive neurons and nerve terminals to produce analgesia. ${ }^{17}$ Morphine may also act by inhibiting TRPV1 and/or inhibiting high-voltage activated calcium channels. ${ }^{239}$ Corneal nerves contain opioid receptors, ${ }^{239}$ and opioid analgesics may induce a corneal reflex blockade. ${ }^{218}$ Narcotics also exhibit a range of effects on corneal epithelium. In animal models, an endogenous opioid, called opioid growth factor (OGF), inhibits reepithelialization following injury, while the OGF antagonist naltrexone enhances reepithelialization. ${ }^{1}$ While it may not have a negative effect on corneal wound healing, fentanyl's analgesic capacity remains unproven. ${ }^{239}$ Anesthetics have a proven analgesic capacity, yet are toxic at typical doses. Application of dilute anesthetics circumvents their toxicity and delivers adequate corneal analgesia. ${ }^{15}$

\section{F. EVIDENCE-BASED TREATMENT OF CORNEAL NEUROPATHIC PAIN}

Neuropathic pain arises from damaged or dysfunctional sensory nerves. Patients with corneal neuropathic pain report dysesthesias perceived as ocular dryness or phantom pain. ${ }^{20}$ Receptors on free nerve endings in the corneal epithelium are implicated in neuropathic pain. Neuropathic pain may be triggered by damage, inflammatory cells, or extracellular chemicals such as glutamate that, through signaling cascades, increase receptor excitability and/or receptor expression. ${ }^{199}$ Corneal nerve injury or transection (such as LASIK) may impair nerve sensitivity and increase the pain threshold while formation of microneuromas and altered nerve excitability likely generate aberrant nerve impulses and neuropathic sensations in the eye. ${ }^{22}$ Patients with corneal neuropathic pain complain of photophobia and eye discomfort without reduced tear production or surface staining that typically explain such symptoms. Although there is some understanding of the pathogenesis and management of neuropathic pain in the setting of peripheral nerve injury elsewhere, little is known in the context of corneal nerve injury. Therefore, current management of corneal neuropathic pain borrows from treatments available for other conditions such as trigeminal neuralgia.

If corneal neuropathic pain is refractory to topical treatments including contact lenses, then pharmacotherapy that is typically used for pain management may be considered. Treatments may include tricyclic antidepressants (TCAs) such as amitriptyline and the serotonin noradrenaline reuptake inhibitor (SNRI) duloxetine, or anticonvulsant GABA analogs such as gabapentin (Neurontin, Pfizer) and pregabalin (Lyrica, Pfizer). ${ }^{12,71}$ The anticonvulsant carbamazepine may be another option, but its efficacy is offset by poor tolerability. ${ }^{12,71}$ Opioids like tramadol can effectively treat neuropathic pain; however, opioids are not regarded as first-line therapy due to side effects of tolerance, cognitive impairment, and dependence. ${ }^{12,71}$

Several other agents may have a beneficial effect on treating neuropathic pain; however there is insufficient clinical data supporting their use in routine clinical practice. These investigational agents can act by nociceptive block or ablation or by attenuating putative neuropathic signaling molecules and include the alpha2 adrenergic agonist brimonidine 
(Alphagan; Allergan), grape seed extract, minocycline, botulinum toxin, ceftriaxone, and RTX. Brimonidine is topically administered to reduce intraocular pressure. A model of trigeminal-derived neuropathic pain suggests that activation of alpha- 2 adrenergic receptors via binding of an alpha-2 adrenergic agonist may inhibit nociceptive transmission. ${ }^{208}$ Grape seed extract and minocycline have anti-hypernociceptive and pro-neural functions. Grape seed extract may suppress neuropathic sensitization of trigeminal-derived nerves by suppressing CGRP expression and upregulating the glutamate transporter GLAST. ${ }^{37}$ The neuroprotective minocycline also has known antihypernociceptive functions, possibly via anti-inflammatory action. ${ }^{16}$ Experimental models reviewed by Bastos et al. ${ }^{16}$ show the effects of minocycline on neuropathic pain are inconsistently proven; however, a narrow therapeutic window exists for minocycline application to effectively treat hypernociceptive pathologic states. ${ }^{16}$ Ceftriaxone upregulates the glutamate clearance transporter GLT1 in the nervous system, and the combination of minocycline with ceftriaxone potentiates the antihypernociceptive effects of each drug alone. ${ }^{11}$ RTX binds TRPV1, a nociceptive receptor implicated in neuropathic pain. ${ }^{22}$ In experimental animals, RTX provides dosedependent analgesia and preserves the corneal epithelium, blink reflex, and sensation of non-TRPV1 neurons. ${ }^{17}$

\section{G. FUTURE DIRECTIONS}

The role of neurons in the health, healing, scarring, and immunology of the cornea, as well as the responsible molecular and cellular mechanisms, have yet to be fully determined. Therefore, the molecular and cellular changes that occur in primary sensory neurons as a result of disease or trauma, including their regenerative mechanisms, constitute high priority needs, gaps, and opportunities in the field and require further study. Recent laboratory investigations have revealed additional corneal nerve modulators; for example, pigment epithelial-derived factor (PEDF) with DHA enhances regeneration of corneal nerves and return of corneal sensitivity following corneal nerve damage. ${ }^{49}$ Technological advances are revealing the positive role of inflammation in corneal nerve regeneration. ${ }^{163}$ The potential clinical impact is great, as visual impairment as the result of corneal nerve dysfunction adversely affects the qualify of life of millions worldwide. Continued laboratory and clinical investigations are needed to advance our understanding of corneal nerves in health and disease.

\section{H. METHOD OF LITERATURE SEARCH}

In preparing this review, we conducted a Medline and PubMed search of medical literature for the period between 1960 and 2013 using the following key words in various combinations: cornea, corneal nerves, nerve regeneration, neurotrophic keratitis, neurotrophic factors, platelet-rich plasma, autologous serum, umbilical cord serum, alphagan, contact lens, corticosteroids, and minocycline. Individual molecules, disease processes, and surgical procedures as discussed in the review were also used as search terms. In addition, reference lists from the selected articles were used to obtain further references not included in the electronic databases. Articles were critically appraised, and pertinent information was included in this review and cited accordingly. 


\section{Acknowledgments}

We thank James Kubilus, Ph.D. (Tufts University) for contributing to the section on corneal nerve development and Nitin K. Garg (University of Illinois at Chicago) for contributing to the literature search in the section on corneal surgeries causing nerve dysfunction.

Supported by National Eye Institute (NEI) Grants K08EY018874 and R01EY023656 (SJ), NEI core grant EY001792, and Research to Prevent Blindness.

\section{References}

1. Abelson, MB.; Dewey-Mattia, D.; Shapiro, A. [Accessed online Jan 2012.] Finding new uses for ancient drugs. Review of Ophthalmology. Online June 11, 2009. http://www.revophth.com/ content/d/therapeutic_topics/i/1215/c/22882/

2. Acosta MC, Berenguer-Ruiz L, García-Gálvez A, Perea-Tortosa D, Gallar J, Belmonte C. Changes in mechanical, chemical, and thermal sensitivity of the cornea after topical application of nonsteroidal anti-inflammatory drugs. Invest Ophthalmol Vis Sci. 2005 Jan; 46(1):282-6. [PubMed: 15623785]

3. Ahuja Y, Baratz KH, McLaren JW, Bourne WM, Patel SV. Decreased corneal sensitivity and abnormal corneal nerves in Fuchs Endothelial Dystrophy. Cornea. 2012; 31(11):1257-63. [PubMed: 22357383]

4. Akiba M, Maeda N, Yumikake K, Soma T, Nishida K, Tano Y, Chan KP. Ultrahigh-resolution imaging of human donor cornea using full-field optical coherence tomography. J Biomed Opt. 2007 Jul-Aug;12(4):041202. [PubMed: 17867791]

5. Al-Aqaba M, Alomar T, Lowe J, Dua HS. Corneal nerve aberrations in bullous keratopathy. Am J Ophthalmol. 2011; 151(5):840-49.e1. [PubMed: 21310389]

6. Al-Aqaba MA, Fares U, Suleman H, Lowe J, Dua HS. Architecture and distribution of human corneal nerves. Br J Ophthalmol. 2010; 94:784-9. [PubMed: 19889832]

7. Al-Aqaba MA, Otri AM, Fares U, Miri A, Dua HS. Organization of the regenerated nerves in human corneal grafts. Am J Ophthalmol. 2012; 153:29-37. [PubMed: 21907318]

8. Alio JL, Colecha JR, Pastor S, Rodriguez A, Artola A. Symptomatic dry eye treatment with autologous platelet-rich plasma. Ophthalmic Res. 2007; 39:124-9. [PubMed: 17374962]

9. Aloe L, Tirassa P, Lambiase A. The topical application of nerve growth factor as a pharmacological tool for human corneal and skin ulcers. Pharmacol Res. 2008 Apr; 57(4):253-8. [PubMed: 18329283]

10. American Academy of Ophthalmology. [Accessed online Feb 2012.] Eye Health Statistics at a Glance. http://www.aao.org/newsroom/press_kit/upload/Eye_Stats_3-5-07

11. Amin B, Hajhashemi V, Hosseinzadeh H, Abnous Kh. Antinociceptive evaluation of ceftriaxone and minocycline alone and in combination in a neuropathic pain model in rat. Neurosci. 2012; 224:15-25.

12. Attal N, Cruccu G, Baron R, Haanpää M, Hansson P, Jensen TS, Nurmikko T. EFNS guidelines on the pharmacological treatment of neuropathic pain: 2010 revision. Eur J Neurol. 2010; 17(9): 1113-e88. [PubMed: 20402746]

13. Auran JD, Koester CJ, Kleiman NJ, Rapaport R, Bomann JS, Wirotsko BM, Florakis GJ, Koniarek JP. Scanning slit confocal microscopic observation of cell morphology and movement within the normal human anterior cornea. Ophthalmology. 1995; 102:33-41. [PubMed: 7831039]

14. Bahn RS. Graves' Ophthalmopathy. N Engl J Med. 2010; 362:726-738. [PubMed: 20181974]

15. Ball IM, Seabrook J, Desai N, Allen L, Anderson S. Dilute proparacaine for the management of acute corneal injures in the emergency department. CJEM. 2010; 12(5):389-96. [PubMed: 20880433]

16. Bastos LF, de Oliveira AC, Watkins LR, Moraes MF, Coelho MM. Tetracyclines and pain. Naunyn Schmiedebergs Arch Pharmacol. 2012; 385(3):225-41. [PubMed: 22282331]

17. Bates BD, Mitchell K, Keller JM, Chan CC, Swaim WD, Yaskovich R, Mannes AJ, Iadarola MJ. Prolonged analgesic response of cornea to topical resiniferatoxin, a potent TRPV1 agonist. Pain. 2010; 149:522-8. [PubMed: 20403666] 
18. Bee J. The development and pattern of innervation of the avian cornea. Dev Biol. 1982; 92(1):515. [PubMed: 6179807]

19. Belmonte, C. Corneal Nerves: Function. In: Dartt, DA.; Bex, P.; D’Amore, P., et al., editors. Ocular Periphery and Disorders. Academic Press; San Diego, CA: 2011. p. 162

20. Belmonte C. Eye dryness sensations after refractive surgery: impaired tear secretion or "phantom" cornea? J Refract Surg. 2007 Jun; 23(6):598-602. [PubMed: 17598580]

21. Belmonte C, Acosta MC, Gallar J. Neural basis of sensation in intact and injured corneas. Exp Eye Res. 2004 Mar; 78(3):513-25. [PubMed: 15106930]

22. Belmonte C, Aracil A, Acosta MC, Luna C, Gallar J. Nerves and sensations from the eye surface. Ocul Surf. 2004 Oct; 2(4):248-53. [PubMed: 17216099]

23. Belmonte C, Garcia-Hirschfeld J, Gallar J. Neurobiology of ocular pain. Prog Ret Eye Res. 1997; 16(1):117-56.

24. Benítez-del-Castillo JM, Acosta MC, Wassfi MA, Díaz-Valle D, Gegúndez JA, Fernandez C, García-Sánchez J. Relation between corneal innervation with confocal microscopy and corneal sensitivity with noncontact esthesiometry in patients with dry eye. Invest Ophthalmol Vis Sci. 2007 Jan; 48(1):173-81. [PubMed: 17197530]

25. Benítez-del-Castillo JM, del Rio T, Iradier T, Hernández JL, Castillo A, Garcia-Sanchez J. Decrease in tear secretion and corneal sensitivity after laser in situ keratomileusis. Cornea. 2001; 20:30-32. [PubMed: 11188999]

26. Benowitz LI, Popovich PG. Inflammation and axon regeneration. Curr Opin Neurol. 2011; 24:57783. [PubMed: 21968547]

27. Beuerman RW, McDonald MB, Zhang D, Varnell RJ, Thompson HW. Diclofenac sodium attenuates neural activity after photorefractive keratectomy in rabbits. J Refract Surg. 1996; 12(7): 783-91. [PubMed: 8970025]

28. Beuerman RW, Schimmelpfennig B. Sensory denervation of the rabbit cornea affects epithelial properties. Exp Neurol. 1980; 69:196-201. [PubMed: 7389846]

29. Bochdalek V, et al. Über die Nerven der durchsichtigen Hornhaut and über einiges anderweitiges Verhalten der letzteren. Med Jb Oest Staates. 1839; 29:185-94. 398-412.

30. Bock F, Onderka J, Rummelt C, Dietrich T, Bachmann B, Kruse FE, Schlötzer-Schrehardt U, Cursiefen C. Safety profile of topical VEGF neutralization at the cornea. Invest Ophthalmol Vis Sci. 2009; 50(5):2095-102. [PubMed: 19151400]

31. Bonilla IE, Tanabe K, Strittmatter SM. Small proline-rich repeat protein 1A is expressed by axotomized neurons and promotes axonal outgrowth. J Neurosci. 2002; 22:1303-1315. [PubMed: 11850458]

32. Bonini S, Lambiase A, Rama P, Caprioglio G, Aloe L. Topical treatment with nerve growth factor for neurotrophic keratitis. Ophthalmology. 2000; 107(7):1347-51. discussion 1351-2. [PubMed: 10889110]

33. Bonini S, Rama P, Olzi D, Lambiase A. Neurotrophic keratitis. Eye (Lond). 2003 Nov; 17(8):989_ 95. [PubMed: 14631406]

34. Bragheeth MA, Dua HS. Corneal sensation after myopic and hyperopic LASIK: clinical and confocal microscopic study. Br J Ophthalmol. 2005 May; 89(5):580-5. [PubMed: 15834089]

35. Brookes NH, Loh IP, Clover GM, Poole CA, Sherwin T. Involvement of corneal nerves in the progression of keratoconus. Exp Eye Res. 2003; 77:515-524. [PubMed: 12957150]

36. Brown SM, Lamberts DW, Reid TW, Nishida T, Murphy CJ. Neurotrophic and anhidrotic keratopathy treated with substance P and insulinlike growth factor 1. Arch Ophthalmol. 1997; 115:926-7. [PubMed: 9230840]

37. Cady RJ, Hirst JJ, Durham PL. Dietary grape seed polyphenols repress neuron and glia activation in trigeminal ganglion and trigeminal nucleus caudalis. Mol Pain. 2010; 6:91. [PubMed: 21143976]

38. Calvillo MP, McLaren JW, Hodge DO, Bourne WM. Corneal reinnervation after LASIK: prospective 3-year longitudinal study. Invest Ophthalmol Vis Sci. 2004 Nov; 45(11):3991-6. [PubMed: 15505047] 
39. Caporossi A, Mazzotta C, Baiocchi S, Caporossi T, Paradiso AL. Transepithelial corneal collagen crosslinking for keratoconus: qualitative investigation by in vivo HRT II confocal analysis. Eur J Ophthalmol. 2012; 22(Suppl 7):S81-8. [PubMed: 22344471]

40. Carrasco E, Blum M, Weickert CS, Casper D. Epidermal growth factor receptor expression is related to post-mitotic events in cerebellar development: regulation by thyroid hormone. Brain Res Dev Brain Res. 2003; 140(1):1-13.

41. Ceccuzzi R, Zanardi A, Fiorentino A, Tinelli C, Bianchi PE. Corneal sensitivity in keratoconus after penetrating and deep anterior lamellar keratoplasty. Ophthalmologica. 2010; 224(4):247-50. [PubMed: 20110740]

42. Chaudhary S, Namavari A, Yco L, Chang JH, Sonawane S, Khanolkar V, Sarkar J, Jain S. Neurotrophins and nerve regeneration-associated genes are expressed in the cornea after lamellar flap surgery. Cornea. 2012; 31(12):1460-7. [PubMed: 22673847]

43. Choi JA, Chung SH. Combined application of autologous serum eye drops and silicone hydrogel lenses for the treatment of persistent epithelial defects. Eye \& Contact Lens. 2011; 37:370-3. [PubMed: 21983552]

44. Chuck RS, Quiros PA, Perez AC, McDonnell PJ. Corneal sensation after laser in situ keratomileusis. J Cataract Refract Surg. 2000; 26:337-9. [PubMed: 10713225]

45. Cohen A, Bray GM, Aguayo AJ. Neurotrophin-4/5 (NT-4/5) increases adult rat retinal ganglion cell survival and neurite outgrowth in vitro. J Neurobiol. 1994; 25(8):953-9. [PubMed: 7964706]

46. Conrad AH, Strafuss JM, Wittman MD, Conway S, Conrad GW. Thyroxine increases the rate but does not alter the pattern of innervation during embryonic chick corneal development. Invest Ophthalmol Vis Sci. 2008; (1):139-53. [PubMed: 18172086]

47. Conrad AH, Zhang Y, Walker AR, Olberding LA, Hanzlick A, Zimmer AJ, Morffi R, Conrad GW. Thyroxine affects expression of KSPG-related genes, the carbonic anhydrase II gene, and KS sulfation in the embryonic chicken cornea. Invest Ophthalmol Vis Sci. 2006; 47(1):120-32. [PubMed: 16384953]

48. Corfas G, Velardez MO, Ko CP, Ratner N, Peles E. Mechanisms and roles of axon-Schwann cell interactions. Journ Neurosci. 2004; 24(42):9250-60.

49. Cortina MS, He J, Li N, Bazan NG, Bazan HEP. Recovery of corneal sensitivity, calcitonin generelated peptide-positive nerves, and increased wound healing induced by pigment epithelialderived factor plus docosahexaenoic acid after experimental surgery. Arch Ophthalmol. 2012; 130(1):76-83. [PubMed: 21911652]

50. Cosar CB, Cohen EJ, Rapuano CJ, Maus M, Penne R, Flanagan JC, Laibson PR. Tarsorrhaphy: clinical experience from a cornea practice. Cornea. 2001; 20(8):787-91. [PubMed: 11685052]

51. Cruzat A, Pavan-Langston D, Hamrah P. In vivo confocal microscopy of corneal nerves: analysis and clinical correlation. Semin Ophthalmol. 2010; 25(5-6):171-7. [PubMed: 21090996]

52. Cruzat A, Witkin D, Baniasadi N, Zheng L, Ciolino JB, Jurkunas UV, Chodosh J, Pavan-Langston D, Dana R, Hamrah P. Inflammation and the nervous system: The connection in the cornea in patients with infectious keratitis. Invest Ophthalmol Vis Sci. 2011; 52(8):5136-43. [PubMed: 21460259]

53. Darwish T, Brahma A, Efron N, O’Donnell C. Subbasal nerve regeneration after penetrating keratoplasty. Cornea. 2007 Sep; 26(8):935-40. [PubMed: 17721291]

54. Darwish T, Brahma A, O’Donnell C, Efron N. Subbasal nerve fiber regeneration after LASIK and LASEK assessed by noncontact esthesiometry and in vivo confocal microscopy: prospective study. J Cataract Refract Surg. 2007 Sep; 33(9):1515-21. [PubMed: 17720064]

55. Davis PJ, Davis FB, Mousa SA. Thyroid hormone-induced angiogenesis. Curr Cardiol Rev. 2009; 5(1):12-16. [PubMed: 20066142]

56. De Castro F, Silos-Santiago I, De Armentia MI, Barbacid M, Belmonte C. Corneal innervation and sensitivity to noxious stimuli in trkA knockout mice. European Journal of Neuroscience. 1998; 10(1):146-52. [PubMed: 9753121]

57. Donnenfeld ED, Ehrenhaus M, Solomon R, Mazurek J, Rozell JC, Perry HD. Effect of hinge width on corneal sensation and dry eye after laser in situ keratomileusis. J Cataract Refract Surg. 2004; 30(4):790-7. [PubMed: 15093640] 
58. Donnenfeld E, Pflugfelder SC. Topical ophthalmic cyclosporine: pharmacology and clinical uses. Surv Ophthalmol. 2009; 54(3):321-38. [PubMed: 19422961]

59. Edén U, Riise R, Tornqvist K. Corneal involvement in congenital aniridia. Cornea. 2010; 29(10): 1096-1102. [PubMed: 20567200]

60. Efron N. Putting vital stains in context. Clin Exp Optom. 2012 Oct 10. Epub ahead of print.

61. Erie EA, McLaren JW, Kittleson KM, Patel SV, Erie JC, Bourne WM. Corneal subbasal nerve density: a comparison of two confocal microscopes. Eye Contact Lens. 2008 Nov; 34(6):322-5. [PubMed: 18997541]

62. Erie JC. Corneal wound healing after photorefractive keratectomy: a 3-year confocal microscopy study. Transactions of the American Ophthalmological Society. 2003; 101:293-333. [PubMed: 14971584]

63. Erie JC, McLaren JW, Hodge DO, Bourne WM. Recovery of corneal subbasal nerve density after PRK and LASIK. Am J Ophthalmol. 2005 Dec; 140(6):1059-1064. [PubMed: 16376651]

64. Erie JC, McLaren JW, Hodge DO, Bourne WM. The effect of age on the corneal subbasal nerve plexus. Cornea. 2005 Aug; 24(6):705-9. [PubMed: 16015090]

65. Erie JC, McLaren JW, Patel SV. Confocal microscopy in ophthalmology. Am J Ophthalmol. 2009; 148(5):639-46. [PubMed: 19674730]

66. Esquenazi S, Bazan HE, Bui V, He J, Kim DB, Bazan NG. Topical combination of NGF and DHA increases rabbit corneal nerve regeneration after photorefractive keratectomy. Invest Ophthalmol Vis Sci. 2005; 46:3121-7. [PubMed: 16123410]

67. Fagerholm P, Lagali NS, Carlsson DJ, Merrett K, Griffith M. Corneal regeneration following implantation of a biomimetic tissue-engineered substitute. Clin Transl Sci. 2009; 2:162-4. [PubMed: 20443883]

68. Fan JC, Patel DV, McGhee CN. Long-term microstructural changes following epikeratophakia: in vivo confocal microscopy study. J Cataract Refract Surg. 2008 Oct; 34(10):1793-8. [PubMed: 18812135]

69. Farrag TY, Lehar M, Verhaegen P, Carson KA, Byrne PJ. Effect of platelet rich plasma and fibrin sealant on facial nerve regeneration in a rat model. Laryngoscope. 2007; 117(1):157-65. [PubMed: 17202946]

70. Fernyhough P, Mill JF, Roberts JL, Ishii DN. Stabilization of tubulin mRNAs by insulin and insulin-like growth factor I during neurite formation. Brain Res Mol Brain Res. 1989; 6(2-3):10920. [PubMed: 2693875]

71. Finnerup NB, Otto M, Jensen TS, Sindrup SH. An evidence-based algorithm for the treatment of neuropathic pain. MedGenMed. 2007; 9(2):36. [PubMed: 17955091]

72. Foldenauer ME, McClellan SA, Barrett RP, Zhang Y, Hazlett LD. Substance P affects growth factors in Pseudomonas aeruginosa-infected mouse corneas. Cornea. 2012; 31(10):1176-88. [PubMed: 22722806]

73. Fong KP, Barry C, Tran AN, Traxler EA, Wannemacher KM, Tang HY, Speicher KD, Blair IA, Speicher DW, Grosser T, Brass LF. Deciphering the human platelet sheddome. Blood. 2010; 117(1):e15-26. [PubMed: 20962327]

74. Foster TE, Puskas BL, Mandelbaum BR, Gerhardt MB, Rodeo SA. Platelet-rich plasma. From basic science to clinical applications. Am J Sports Med. 2009; 37(11):2259-72. [PubMed: 19875361]

75. Fu Y, Liu J, Tseng SC. Ocular surface deficits contributing to persistent epithelial defect after penetrating keratoplasty. Cornea. 2012; 31(7):723-9. [PubMed: 22495035]

76. Fukiage C, Nakajima T, Takayama Y, Minagawa Y, Shearer TR, Azuma M. PACAP induces neurite outgrowth in cultured trigeminal ganglion cells and recovery of corneal sensitivity after flap surgery in rabbits. Am J Ophthalmol. 2007 Feb; 143(2):255-262. [PubMed: 17173850]

77. Gaynes BI, Onyekwuluje A. Topical ophthalmic NSAIDs: a discussion with focus on nepafenac ophthalmic suspension. Clin Ophthalmol. 2008; 2(2):355-68. [PubMed: 19668727]

78. Ghanem VC, Ghanem RC, de Oliveira R. Postoperative pain after corneal collagen cross-linking. Cornea. 2013; 32(1):20-4. [PubMed: 22547128] 
79. Gil-Cazorla R, Teus MA, Arranz-Márquez E. Comparison of silicone and non-silicone hydrogen soft contact lenses used as a bandage after LASEK. J Refract Surg. 2008; 24:199-203. [PubMed: 18297946]

80. Guidera AC, Luchs JI, Udell IJ. Keratitis, ulceration, and perforation associated with topical nonsteroidal anti-inflammatory drugs. Ophthalmology. 2001; 108(5):936-44. [PubMed: 11320025]

81. Gulati, A.; Dana, R. Ch. 28 Keratoconjuctivitis sicca: Clinical Aspects. In: Smolin, G.; Foster, CS.; Azar, DT.; Dohlman, CH., editors. Smolin and Thoft's The cornea: scientific foundations and clinical practice. 4. Lippincott Williams \& Wilkins; Philadelphia, PA: 2005. p. 607

82. Guttmann-Raviv N, Shraga-Heled N, Varshavsky A, Guimaraes-Sternberg C, Kessler O, Neufeld G. Semaphorin-3A and semaphorin-3F work together to repel endothelial cells and to inhibit their survival by induction of apoptosis. J Biol Chem. 2007; 282(36):26294-305. [PubMed: 17569671]

83. Hamrah P, Cruzat A, Dastjerdi MH, Zheng L, Shahatit BM, Bayhan HA, Dana R, Pavan-Langston D. Corneal sensation and subbasal nerve alterations in patients with Herpes Simplex Keratitis: an in vivo confocal microscopy study. Ophthalmology. 2010; 117(10):1930-6. [PubMed: 20810171]

84. Hanna C, Bicknell DS, O'Brien JE. Cell turnover in the adult human eye. Arch Ophthalmol. 1961; 65:695, 8. [PubMed: 13711260]

85. Harris LW, Purves D. Rapid remodeling of sensory endings in the corneas of living mice. $\mathbf{J}$ Neurosci. 1989; 9:2210-4. [PubMed: 2723770]

86. He J, Bazan HE. Mapping the nerve architecture of diabetic human corneas. Ophthalmology. 2012; 119(5):956-64. [PubMed: 22325488]

87. He J, Bazan NG, Bazan HE. Mapping the entire human corneal nerve architecture. Exp Eye Res. 2010; 91(4):513-23. [PubMed: 20650270]

88. Heigle TJ, Pflugfelder SC. Aqueous tear production in patients with neurotrophic keratitis. Cornea. 1996; 15(2):135-8. [PubMed: 8925660]

89. Heinz C, Eckstein A, Steuhl KP, Meller D. Amniotic membrane transplantation for reconstruction of corneal ulcer in Graves ophthalmopathy. Cornea. 2004; 23(5):524-6. [PubMed: 15220741]

90. Herrmann WA, Shah C, Gabler B, Winkler von Mohrenfels C, Hufendiek K, Lohmann CP. Corneal sensation after laser epithelial keratomileusis for the correction of myopia. Graefes Arch Clin Exp Ophthalmol. 2005 Jan; 243(1):33-7. [PubMed: 15316794]

91. Hillenaar T, van Cleynenbreugel H, Remeijer L. How Normal is the Transparent Cornea? Effects of Aging on Corneal Morphology. Ophthalmology. 2012; 119(2):241-8. [PubMed: 22035579]

92. Hirata A, Masaki T, Motoyoshi K, Kamakura K. Intrathecal administration of nerve growth factor delays GAP 43 expression and early phase regeneration of adult rat peripheral nerve. Brain Res. 2002; 19;944(1-2):146-56.

93. Hiura A, Nakagawa H. Innervation of TRPV1-, PGP-, and CGRP-immunoreactive fibers in the subepithelial layer of a whole mount preparation of the rat cornea. Okajimas Folia Anat Jpn. 2012; 89(2):47-50. [PubMed: 23117304]

94. Hossain P, Sachdev A, Malik RA. Early detection of diabetic peripheral neuropathy with corneal confocal microscopy. Lancet. 2005 Oct 15-21; 366(9494):1340-3. [PubMed: 16226599]

95. Hu Y, Matsumoto Y, Adan ES, Dogru M, Fukagawa K, Tsubota K, Fujishima H. Corneal in vivo confocal scanning laser microscopy in patients with atopic keratoconjunctivitis. Ophthalmology. 2008; 115(11):2004-12. [PubMed: 18584874]

96. Huang JC, Sun CC, Chang CK, Ma DH, Lin YF. Effect of hinge position on corneal sensation and dry eye parameters after femtosecond laser-assisted LASIK. J Refract Surg. 2012; 28(9):625-31. [PubMed: 22947290]

97. Isawi H, Dhaliwal DK. Corneal melting and perforation in Stevens Johnson syndrome following topical bromfenac use. J Cataract Refract Surg. 2007; 33(9):1644-6. [PubMed: 17720085]

98. Isenmann S, Klöcker N, Gravel C, Bähr M. Protection of axotomized retinal ganglion cells by adenovirally delivered BDNF in vivo. Eur J Neurosci. 1998; 10(8):2751-56. [PubMed: 9767407]

99. Ishida S, Usui T, Yamashiro K, Kaji Y, Ahmed E, Carrasquillo KG, Amano S, Hida T, Oguchi Y, Adamis AP. VEGF164 is proinflammatory in the diabetic retina. Invest Ophthalmol Vis Sci. 2003; 44(5):2155-62. [PubMed: 12714656] 
100. Jafarinasab MR, Zarei-Ghanavati S, Kanavi MR, Karimian F, Soroush MR, Javadi MA. Confocal microscopy in chronic and delayed mustard gas keratopathy. Cornea. 2010; 29(8):889-94. [PubMed: 20489576]

101. Jalbert I, Papas E, Sweeney DF, Stapleton F. Instrument, diurnal, and day to day repeatability of in vivo measurements of the central human cornea using slit scanning confocal microscopy and modified optical pachometry. Invest Ophthalmol Vis Sci. 2002; 43 E-Abstract 1713.

102. Jalbert I, Stapleton F, Papas E, Sweeney DF, Coroneo M. In vivo confocal microscopy of the human cornea. Br J Ophthalmol. 2003; 87:225-36. [PubMed: 12543757]

103. Javadi MA, Rezaei Kanavi M, Faramarzi A, Feizi S, Azizi F, Javadi F. Confocal scan imaging and impression cytology of the cornea in a case of multiple endocrine neoplasia type-2b. J Ophthalmic Vis Res. 2012; 7(2):176-9. [PubMed: 23275828]

104. Jayasena CS, Flood WD, Koblar SA. High EphA3 expressing ophthalmic trigeminal sensory axons are sensitive to ephrin-A5-Fc: implications for lobe specific axon guidance. Neuroscience. 2005; 135(1):97-109. [PubMed: 16054765]

105. Jeng BH, Dupps WJ Jr. Autologous serum 50\% eyedrops in the treatment of persistent corneal epithelial defects. Cornea. 2009; 28(10):1104-8. [PubMed: 19730088]

106. Jones MA, Marfurt CF. Peptidergic innervation of the rat cornea. Exp Eye Res. 1998; 66(4):42135. [PubMed: 9593636]

107. Kauffmann T, Bodanowitz S, Hesse L, Kroll P. Corneal reinnervation after photorefractive keratectomy and laser in situ keratomileusis: an in vivo study with a confocal videomicroscope. Ger J Ophthalmol. 1996; 5(6):508-12. [PubMed: 9479547]

108. Khokhar S, Natung T, Sony P, Sharma N, Agarwal N, Vajpayee RB. Amniotic membrane transplantation in refractory neurotrophic corneal ulcers: a randomized, controlled clinical trial. Cornea. 2005 Aug; 24(6):654-60. [PubMed: 16015082]

109. Kim EC, Lee WS, Kim MS. The inhibitory effects of bevacizumab eye drops on NGF expression and corneal wound healing in rats. Invest Ophthalmol Vis Sci. 2010; 51(9):4569-73. [PubMed: 20393106]

110. Kim HC, Cho YJ, Ahn CW, Park KS, Kim JC, Nam JS, Im YS, Lee JE, Lee SC, Lee HK. Nerve growth factor and expression of its receptors in patients with diabetic neuropathy. Diabet Med. 2009; 26(12):1228-34. [PubMed: 20002474]

111. Kim SW, Ha BJ, Kim EK, Tchah H, Kim TI. The effect of topical bevacizumab on corneal neovascularization. Ophthalmology. 2008; 115(6):e33-8. [PubMed: 18439681]

112. Kobayashi NR, Fan DP, Giehl KM, Bedard AM, Wiegand SJ, Tetzlaff W. BDNF and NT-4/5 prevent atrophy of rat rubrospinal neurons after cervical axotomy, stimulate GAP-43 and Ta1tubulin mRNA expression, and promote axonal regeneration. J Neurosci. 1997; 17(24):9583-95. [PubMed: 9391013]

113. Kubilus JK, Linsenmayer TF. Developmental guidance of embryonic corneal innervation: roles of Semaphorin 3A and Slit2. Dev Biol. 2010; 344(1):172-84. [PubMed: 20471970]

114. Kumano Y, Matsui H, Zushi I, Mawatari A, Matsui T, Nishida T, Miyazaki M. Recovery of corneal sensation after myopic correction by laser in situ keratomileusis with a nasal or superior hinge. J Cataract Refract Surg. 2003; 29:757-61. [PubMed: 12686245]

115. Kumar RL, Koenig SB, Covert DJ. Corneal sensation after descemet stripping and automated endothelial keratoplasty. Cornea. 2010; 29(1):13-8. [PubMed: 19907297]

116. Kurbanyan K, Hoesl LM, Schrems WA, Hamrah P. Corneal nerve alterations in acute Acanthamoeba and fungal keratitis: an in vivo confocal microscopy study. Eye. 2012; 26:126-32. [PubMed: 22079969]

117. Lalive PH, Truffert A, Magistris MR, Landis T, Dosso A. Peripheral autoimmune neuropathy assessed using corneal in vivo confocal microscopy. Arch Neurol. 2009; 66(3):403-5. [PubMed: 19273761]

118. Lambiase A, Coassin M, Costa N, Lauretti P, Micera A, Ghinelli E, Aloe L, Rama P, Bonini S. Topical treatment with nerve growth factor in an animal model of herpetic keratitis. Graefes Arch Clin Exp Ophthalmol. 2008; 246(1):121-7. [PubMed: 17479276] 
119. Lambiase A, Merlo D, Mollinari C, Bonini P, Rinaldi AM, D’Amato M, Micera A, Coassin M, Rama P, Bonini S, Garaci E. Molecular basis for keratoconus: Lack of TrkA expression and its transcriptional repression by Sp3. PNAS. 2005; 102(46):16795-800. [PubMed: 16275928]

120. Lambiase A, Rama P, Bonini S, Caprioglio G, Aloe L. Topical treatment with nerve growth factor for corneal neurotrophic ulcers. N Engl J Med. 1998; 338:1174-80. [PubMed: 9554857]

121. Lee HK, Ryu IH, Seo KY, Hong S, Kim HC, Kim EK. Topical 0. 1\% prednisolone lowers nerve growth factor expression in keratoconjunctivitis sicca patients. Ophthalmology. 2006; 113(2): 198-205. [PubMed: 16360211]

122. Lee SJ, Kim JK, Seo KY, Kim EK, Lee HK. Comparison of corneal nerve regeneration and sensitivity between LASIK and laser epithelial keratomileusis (LASEK). Am J Ophthalmol. 2006 Jun; 141(6):1009-1015. [PubMed: 16765667]

123. Leiper LJ, Ou J, Walczysko P, Kucerova R, Lavery DN, West JD, Collinson JM. Control of patterns of corneal innervation by Pax6. Invest Ophthalmol Vis Sci. 2009; 50(3):1122-8. [PubMed: 19029029]

124. Lema I, Duran JA. Inflammatory molecules in the tears of patients with keratoconus. Ophthalmology. 2005; 112(4):654-9. [PubMed: 15808258]

125. Li H, Xie W, Strong JA, Zhang JM. Systemic anti-inflammatory corticosteroid reduces mechanical pain behavior, sympathetic sprouting, and elevation of proinflammatory cytokines in a rat model of neuropathic pain. Anesthesiology. 2007; 107(3):469-77. [PubMed: 17721250]

126. Li S, Nikulina K, DeVoss J, et al. Small proline-rich protein 1B (SPRR1B) is a biomarker for squamous metaplasia in dry eye disease. Invest Ophthalmol Vis Sci. 2008; 49:34-41. [PubMed: 18172072]

127. Li Z, Burns AR, Han L, Rumbaut RE, Smith CW. IL-17 and VEGF are necessary for efficient corneal nerve regeneration. Am J Pathol. 2011; 178(3):1106-16. [PubMed: 21356362]

128. Lim MS, Nam SH, Kim SJ, Kang SY, Lee YS, Kang KS. Signaling pathways of the early differentiation of neural stem cells by neurotrophin-3. Biochem Biophys Res Com. 2007; 357(4): 903-9. [PubMed: 17466268]

129. Lindholm D, Heumann R, Hengerer B, Thoenen H. Interleukin 1 increases stability and transcription of mRNA encoding nerve growth factor in cultured rat fibroblasts. J Biol Chem. 1988; 263:16348-51. [PubMed: 3263368]

130. Ling JD, Gire A, Pflugfelder SC. PROSE therapy used to minimize corneal trauma in patients with corneal epithelial defects. Am J Ophthalmol. 2013; 155(4):615-9. [PubMed: 23218704]

131. Liu L, Hartwig D, Harloff S, Herminghaus P, Wedel T, Geerling G. An optimized protocol for the production of autologous serum eyedrops. Graefes Arch Clin Exp Ophthalmol. 2005; 243(7): 706-14. [PubMed: 15756576]

132. Lopatina T, Kalinina N, Karagyaur M, Stambolsky D, Rubina K, Revischin A, Pavlova G, Parfyonova Y, Tkachuk V. Adipose-derived stem cells stimulate regeneration of peripheral nerves: BDNF secreted by these cells promotes nerve healing and axon growth de novo. PLoS One. 2011; 14;6(3):e17899.

133. Lwigale PY. Embryonic origin of avian corneal sensory nerves. Dev Biol. 2001; 239(2):323-37. [PubMed: 11784038]

134. Lwigale PY, Bronner-Fraser M. Lens-derived Semaphorin3A regulates sensory innervation of the cornea. Dev Biol. 2007 Jun 15; 306(2):750-9. [PubMed: 17499699]

135. Madduri S, Papaloïzos M, Gander B. Synergistic effect of GDNF and NGF on axonal branching and elongation in vitro. Neurosci Res. 2009; 65(1):88-97. [PubMed: 19523996]

136. Mannion LS, Tromans C, O’Donnell C. Corneal nerve structure and function in keratoconus: a case report. Eye Contact Lens. 2007 Mar; 33(2):106-8. [PubMed: 17496705]

137. Marfurt, CF. Corneal Nerves: Anatomy. In: Dartt, DA.; Bex, P.; D’Amore, P., et al., editors. Ocular Periphery and Disorders. Academic Press; San Diego, CA: 2011. p. 150

138. Marfurt CF, Cox J, Deek S, Dvorscak L. Anatomy of the human corneal innervation. Exp Eye Res. 2010; 90(4):478-92. [PubMed: 20036654]

139. Martin RE, Bazan NG. Growth-associated protein GAP-43 and nerve cell adhesion molecule in sensory nerves of cornea. Exp Eye Res. 1992; 55(2):307-14. [PubMed: 1426063] 
140. Martin RE, Henken DB, Hill JM. Altered expression and changing distribution of the nerve growth associated protein GAP-43 during ocular HSV-1 infection in the rabbit. J Neurovirol. 1996; 2(2):127-35. [PubMed: 8799204]

141. Martin XY, Safran AB. Corneal hypoesthesia. Surv Ophthalmol. 1988; 33(1):28-40. [PubMed: 3051467]

142. Matsui H, Kumano Y, Zushi I, Yamada T, Matsui T, Nishida T. Corneal sensation after correction of myopia by photorefractive keratectomy and laser in situ keratomileusis. Journ Cat Refract Surg. 2001; 27:370-3.

143. Matsumoto Y, Dogru M, Goto E, Ohashi Y, Kojima T, Ishida R, Tsubota K. Autologous serum application in the treatment of neurotrophic keratopathy. Ophthalmology. 2004 Jun; 111(6): 1115-20. [PubMed: 15177961]

144. Mazzotta C, Traversi C, Baiocchi S, Caporossi O, Bovone C, Sparano MC, Balestrazzi A, Caporossi A. Corneal healing after riboflavin ultraviolet-A collagen cross-linking determined by confocal laser scanning microscopy in vivo: early and late modifications. Am J Ophthalmol. 2008 Oct; 146(4):527-533. [PubMed: 18672225]

145. McGhee CN, Dean S, Danesh-Meyer H. Locally administered ocular corticosteroids: benefits and risks. Drug Saf. 2002; 25(1):33-55. [PubMed: 11820911]

146. McKenna CC, Lwigale PY. Innvervation of the mouse cornea during development. Invest Ophthalmol Vis Sci. 2011; 52(1):30-35. [PubMed: 20811061]

147. McKenna CC, Munjaal RP, Lwigale PY. Distinct roles for neuropilin1 and neuropilin2 during mouse corneal innervation. PLoS One. 2012; 7(5):e37175. [PubMed: 22615927]

148. Melcangi RC, Giatti S, Pesaresi M, Calabrese D, Mitro N, Caruso D, Garcia-Segura LM. Role of neuroactive steroids in the peripheral nervous system. Front Endocrinol (Lausanne). 2011; 2:104. [PubMed: 22654839]

149. Meller D, Pauklin M, Thomasen H, Westekemper H, Steuhl KP. Amniotic membrane transplantation in the human eye. Dtsch Arztebl Int. 2011; 108(14):243-8. [PubMed: 21547164]

150. Michaeli A, Slomovic AR, Sakhichand K, Rootman DS. Effect of laser in situ keratomileusis on tear secretion and corneal sensitivity. J Refract Surg. 2004; 20:379-83. [PubMed: 15307401]

151. Mimura T, Amano S, Fukuoka S, Honda N, Arita R, Ochiai M, Yanagisawa M, Usui T, Ono K, Araki F, Yamagami S, Araie M, Awaya Y. In vivo confocal microscopy of hereditary sensory and autonomic neuropathy. Curr Eye Res. 2008 Nov; 33(11):940-5. [PubMed: 19085376]

152. Mitchison T, Kirschner M. Cytoskeletal dynamics and nerve growth. Neuron. 1988; 1(9):761-72. [PubMed: 3078414]

153. Mocan MC, Durukan I, Irkec M, Orhan M. Morphologic alterations of both the stromal and subbasal nerves in the corneas of patients with diabetes. Cornea. 2006 Aug; 25(7):769-73. [PubMed: 17068451]

154. Moilanen JA, Holopainen JM, Vesaluoma MH, Tervo TM. Corneal recovery after lasik for high myopia: a 2-year prospective confocal microscopic study. Br J Ophthalmol. 2008 Oct; 92(10): 1397-402. [PubMed: 18650214]

155. Molnár I, Bokk A. Decreased nerve growth factor levels in hyperthyroid Graves' ophthalmopathy highlighting the role of neuroprotective factor in autoimmune thyroid diseases. Cytokine. 2006; 35(3-4):109-11. [PubMed: 17008110]

156. Müller LJ, Marfurt CF, Kruse F, Tervo TMT. Corneal nerves: structure, contents and function. Exp eye Research. 2003; 76:521-542.

157. Müller LJ, Pels L, Vrensen GF. Ultrastructural organization of human corneal nerves. Invest Opthalmol Visc Sci. 1996; 37(4):476-88.

158. Müller LJ, Vrensen GF, Pels L, Cardozo BN, Willekens B. Architecture of human corneal nerves. Invest Ophthalmol Vis Sci. 1997; 38:985-94. [PubMed: 9112994]

159. Murata Y, Masuko S. Peripheral and central distribution of TRPV1, substance P and CGRP of rat corneal neurons. Brain Res. 2006; 1085(1):87-94. [PubMed: 16564032]

160. Murphy PJ, Patel S, Kong N, Ryder RE, Marshall J. Noninvasive assessment of corneal sensitivity in young and elderly diabetic and nondiabetic subjects. Invest Ophthalmol Vis Sci. 2004 Jun; 45(6):1737-42. [PubMed: 15161834] 
161. Nagasato D, Araki-Sasaki K, Kojima T, Ideta R, Dogru M. Morphological changes of corneal subepithelial nerve plexus in different types of herpetic keratitis. Japanese Journal of Ophthalmology. 2011; 55(5):444-50. [PubMed: 21830060]

162. Nakamura M, Nishida T, Ofuji K, Reid TW, Mannis MJ, Murphy CJ. Synergistic effect of substance $\mathrm{P}$ with epidermal growth factor on epithelial migration in rabbit cornea. Exp Eye Res. 1997; 65(3):321-9. [PubMed: 9299169]

163. Namavari A, Chaudhary S, Chang JH, Yco L, Sonawane S, Khanolkar V, Yue BY, Sarkar J, Jain $\mathrm{S}$. Cyclosporine immunomodulation retards regeneration of surgically transected corneal nerves. Invest Ophthalmol Vis Sci. 2012; 53(2):732-40. [PubMed: 22205605]

164. Namavari A, Chaudhary S, Ozturk O, Chang JH, Yco L, Sonawane S, Katam N, Khanolkar V, Hallak J, Sarkar J, Jain S. Semaphorin 7a links nerve regeneration and inflammation in the cornea. Cornea. 2012; 53(8):4575-85.

165. Namavari A, Chaudhary S, Sarkar J, Yco L, Patel K, Han KY, Yue BY, Chang JH, Jain S. In vivo serial imaging of regenerating corneal nerves after surgical transection in transgenic thy1-YFP mice. Invest Ophthalmol Vis Sci. 2011; 52(11):8025-32. [PubMed: 21896845]

166. Nassaralla BA, McLeod SD, Boteon JE, Nassaralla JJ Jr. The effect of hinge position and depth plate on the rate of recovery of corneal sensation following LASIK. Am J Ophthalmol. 2005; 139:118-24. [PubMed: 15652836]

167. Nassaralla BA, McLeod SD, Nassaralla J. Effect of myopic LASIK on human corneal sensitivity. Opthalmology. 2003; 110:497-502.

168. Nejima R, Miyata K, Tanabe T, Okamoto F, Hiraoka T, Kiuchi T, Oshika T. Corneal barrier function, tear film stability, and corneal sensation after photorefractive keratectomy and laser in situ keratomileusis. Am Journ Ophthalmol. 2005; 139:64-71.

169. Niederer RL, Perumal D, Sherwin T, McGhee CN. Age-related differences in the normal human cornea: a laser scanning in vivo confocal microscopy study. Br J Ophthalmol. 2007 Sep; 91(9): 1165-9. [PubMed: 17389741]

170. Niederer RL, Perumal D, Sherwin T, McGhee CN. Laser scanning in vivo confocal microscopy reveals reduced innervation and reduction in cell density in all layers of the keratoconic cornea. Invest Ophthalmol Vis Sci. 2008 Jul; 49(7):2964-70. [PubMed: 18579760]

171. Nishida T, Chikama T, Sawa M, Miyata K, Matsui T, Shigeta K. Differential contributions of impaired corneal sensitivity and reduced tear secretion to corneal epithelial disorders. Jpn J Ophthalmol. 2012; 56(1):20-5. [PubMed: 22071673]

172. Oble DA, Burton L, Maxwell K, Hassard T, Nathaniel EJH. A comparison of thyroxine- and polyamine-mediated enhancement of rat facial nerve regeneration. Exp Neurol. 2004; 189(1): 105-11. [PubMed: 15296840]

173. Okuno T, Nakatsuji Y, Kumanogoh A. The role of immune semaphorins in multiple sclerosis. FEBS Lett. 2011; 585:3829-35. [PubMed: 21420960]

174. Oliveira-Soto L, Efron N. Morphology of corneal nerves using confocal microscopy. Cornea. 2001; 20:374-84. [PubMed: 11333324]

175. Omoto M, Yoshida S, Miyashita H, Kawakita T, Yoshida K, Kishino A, Kimura T, Shibata S, Tsubota K, Okano H, Shimmura S. The semaphorin 3A inhibitor SM-345431 accelerates peripheral nerve regeneration and sensitivity in a murine corneal transplantation model. PLoS One. 2012; 7(11):e47716. [PubMed: 23152758]

176. Pachigolla G, Prasher P, Di Pascuale MA, McCulley JP, McHenry JG, Mootha VV. Evaluation of the role of ProKera in the management of ocular surface and orbital disorders. Eye \& Contact Lens. 2009; 35(4):172-5. [PubMed: 19474753]

177. Pan S, Li L, Xu Z, Zhao J. Effect of leukemia inhibitory factor on corneal nerve regeneration of rabbit eyes after laser in situ keratomileusis. Neurosci Letters. 2011; 499:99-103.

178. Pascolini D, Mariotti SP. Global estimates of visual impairment: 2010. Br J Ophthalmol. 2012; 96:614-8. [PubMed: 22133988]

179. Pasterkamp RJ, Peschon JJ, Spriggs MK, Kolodkin AL. Semaphorin 7A promotes axon outgrowth through integrins and MAPKs. Nature. 2003; 424:398-405. [PubMed: 12879062] 
180. Patel DV, McGhee CNJ. In vivo confocal microscopy of human corneal nerves in health, in ocular and systemic disease, and following corneal surgery: a review. Br J Ophthalmol. 2009; 93:853-60. [PubMed: 19019923]

181. Patel DV, McGhee CN. Mapping of the normal human corneal subbasal nerve plexus by in vivo laser scanning confocal microscopy. Invest Ophthalmol Vis Sci. 2005 Dec; 46(12):4485-8. [PubMed: 16303938]

182. Patel DV, McGhee CN. Mapping the corneal subbasal nerve plexus in keratoconus by in vivo laser scanning confocal microscopy. Invest Ophthalmol Vis Sci. 2006; 47(4):1348-51. [PubMed: 16565367]

183. Patel DV, Tavakoli M, Craig JP, Efron N, McGhee CJ. Corneal sensitivity and slit scanning in vivo confocal microscopy of the subbasal nerve plexus of the normal central and peripheral human cornea. Cornea. 2009; 28:735-40. [PubMed: 19574916]

184. Patel SV, McLaren JW, Kittleson KM, Bourne WM. Subbasal nerve density and corneal sensitivity after laser in situ keratomileusis: femtosecond laser vs mechanical microkeratome. Arch Opthalmol. 2010; 128:1413-19.

185. Paves H, Saarma M. Neurotrophins as in vitro growth cone guidance molecules for embryonic sensory neurons. Cell Tissue Res. 1997; 290(2):285-97. [PubMed: 9321690]

186. Perez-Santonja JJ, Sakla HF, Cardona C, Chipont E, Alio JL. Corneal sensitivity after photorefractive keratectomy and laser in situ keratomieusis for low myopia. Am J Ophthalmol. 1999; 127:497-504. [PubMed: 10334340]

187. Peyman GA, Rahimy MH, Fernandes ML. Effects of morphine on corneal sensitivity and epithelial wound healing: implications for topical ophthalmic analgesia. Br Journ Opthalmol. 1994; 78:138-41.

188. Qi H, Chuang EY, Yoon KC, de Paiva CS, Shine HD, Jones DB, Pflugfelder SC, Li DQ. Patterned expression of neurotrophic factors and receptors in human limbal and corneal regions. Mol Vis. 2007 Oct 16.13:1934-41. [PubMed: 17982417]

189. Ramaesh K, Ramaesh T, West JD, Dhillon B. Immunolocalisation of leukaemia inhibitory factor in the cornea. Eye. 2004; 18:1006-9. [PubMed: 15060560]

190. Rosen CF, Poon R, Drucker DJ. UVB radiation-activated genes induced by transcriptional and posttranscriptional mechanisms in rat keratinocytes. Am J Physiol. 1995; 268:C846-55. [PubMed: 7733233]

191. Rosenfeld SI. Evaluation and management of post-LASIK dry eye syndrome. Int Ophthalmol Clin. 2010; 50(3):191-9. [PubMed: 20611028]

192. Roszkowska AM, Colosi P, Ferreri FM, Galasso S. Age-related modifications of corneal sensitivity. Ophthalmologica. 2004 Sep-Oct;218(5):350-5. [PubMed: 15334017]

193. Ruddle JB, Mackey DA, Downie NA. Clinical progression of keratoconus following a Vth nerve palsy. Clin Exp Ophthalmol. 2003; 31:363-5.

194. Sakimoto T, Kim TI, Ellenberg D, Fukai N, Jain S, Azar DT, Chang JH. Collagen XVIII and corneal reinnervation following keratectomy. FEBS Lett. 2008 Oct 29; 582(25-26):3674-80. [PubMed: 18840438]

195. Salomão MQ, Ambrósio R Jr, Wilson SE. Dry eye associated with laser in situ keratomileusis: mechanical microkeratome versus femtosecond laser. J Cat Refract Surg. 2009; 35(10):1756-60.

196. Sanjay S, Huang P, Lavanya R. Herpes zoster ophthalmicus. Curr Treat Options Neurol. 2011; 13(1):79-91. [PubMed: 21063920]

197. Sarkar J, Chaudhary S, Namavari A, Ozturk O, Chang JH, Yco L, Sonawane S, Khanolkar V, Hallak J, Jain S. Corneal neurotoxicity due to topical benzalkonium chloride. Invest Ophthalmol Vis Sci. 2012; 53(4):1792-1802. [PubMed: 22410563]

198. Schlemm TFW. Nerven der Cornea. Ammon’ Z Ophthalmol. 1831; 1:113-4.

199. Scholz J, Woolf CJ. The neuropathic pain triad: neurons, immune cells and glia. Nat Neurosci. 2007; 10:1361-8. [PubMed: 17965656]

200. Skene JH, Willard M. Axonally transported proteins associated with axon growth in rabbit central and peripheral nervous systems. J Cell Biol. 1981; 89:96-103. [PubMed: 6164683] 
201. Stachs O, Zhivov A, Kraak R, Stave J, Guthoff R. In vivo three-dimensional confocal laser scanning microscopy of the epithelial nerve structure in the human cornea. Graefes Arch Clin Exp Ophthalmol. 2007 Apr; 245(4):569-75. [PubMed: 16941142]

202. Starkey ML, Davies M, Yip PK, Carter LM, Wong DJN, McMahon SB, Bradbury EJ. Expression of the regeneration-associated protein SPRR1A in primary sensory neurons and spinal cord of the adult mouse following peripheral and central injury. J Comp Neurol. 2009; 513(1):51-68. [PubMed: 19107756]

203. Stern ME. Pathophysiology and allergy of the lacrimal functional unit: what goes wrong with our tear-secreting apparatus? Asian Journal of Ophthalmology. 2005; 7(2):5-8.

204. Sterneck E, Kaplan DR, Johnson PF. Interleukin-6 induces expression of Peripherin and cooperates with Trk receptor signaling to promote neuronal differentiation in PC12 cells. J Neurochem. 1996; 67(4):1365-74. [PubMed: 8858917]

205. Sugaya S, Sakimoto T, Shoji J, Sawa M. Regulation of soluble interleukin-6 (IL-6) receptor release from corneal epithelial cells and its role in the ocular surface. Jpn J Ophthalmol. 2011; 55(3):277-82. [PubMed: 21523377]

206. Takai S, Kinoshita S, Tanaka F, Ikeda M, Tanaka N, Kobayashi T. Prominent corneal nerves in patients with multiple endocrine neoplasia type 2A: diagnostic implications. World J Surg. 1992; 16(4):620-3. [PubMed: 1357828]

207. Takamatsu H, Kumanogh A. Diverse roles for semaphorin-plexin signaling in the immune system. Trends Immunol. 2012; 33:127-35. [PubMed: 22325954]

208. Takeda M, Ikeda M, Tanimoto T, Lipski J, Matsumoto S. Changes of the excitability of rat trigeminal root ganglion neurons evoked by alpha(2)-adrenreceptors. Neuroscience. 2002; 115(3):731-41. [PubMed: 12435412]

209. Tan MH, Bryars J, Moore J. Use of nerve growth factor to treat congenital neurotrophic corneal ulceration. Cornea. 2006; 25(3):352-5. [PubMed: 16633039]

210. Tavakoli M, Hossain P, Malik RA. Clinical applications of corneal confocal microscopy. Clin Ophthalmol. 2008; 2(2):435-45. [PubMed: 19668734]

211. Tavakoli M, Marhsall A, Pitceathly R, Gow D, Roberts ME, Malik RA. Corneal confocal microscopy: a novel means to detect nerve fibre damage in idiopathic small fibre neuropathy. Exp Neurol. 2010; 223(1):245-250. [PubMed: 19748505]

212. Templeton A, Nguyen G, Ash JD, Straub RH, Carr DJ. Chemical sympathectomy increases susceptibility to ocular herpes simplex virus type 1 infection. J Neuroimmunol. 2008 Jun 15; 197(1):37-46. [PubMed: 18495255]

213. Tole S, Mukovozov IM, Huang YW, Magalhaes MA, Yan M, Crow MR, Liu GY, Sun CX, Durocher Y, Glogauer M, Robinson LA. The axonal repellent, Slit2, inhibits directional migration of circulating neutrophils. J Leukoc Biol. 2009; 86(6):1403-15. [PubMed: 19759280]

214. Tominaga M, Julius D. Capsaicin receptor in the pain pathway. Jpn J Pharmacol. 2000; 83:20-4. [PubMed: 10887936]

215. Tong L, Corrales RM, Chen Z, et al. Expression and regulation of cornified envelope proteins in human corneal epithelium. Invest Ophthalmol Vis Sci. 2006; 47:1938-46. [PubMed: 16639001]

216. Tuisku IS, Konttinen YT, Konttinen LM, Tervo TM. Alterations in corneal sensitivity and nerve morphology in patients with primary Sjögren's syndrome. Exp Eye Res. 2008 Jun; 86(6):879-85. [PubMed: 18436208]

217. Ueno H, Ferrari G, Hattori T, Saban DR, Katikireddy KR, Chauhan SK, Dana R. Dependence of corneal stem/progenitor cells on ocular surface innervation. Invest Ophthalmol Vis Sci. 2012; 53(2):867-72. [PubMed: 22232434]

218. Vanbever R, Langers G, Montmayeur S, Préat V. Transdermal delivery of fentanyl: rapid onset of analgesia using skin electroporation. Journal of Controlled Release. 1998; 50:225-35. [PubMed: 9685889]

219. Villani E, Galimberti D, Viola F, Mapelli C, Ratiglia R. The cornea in Sjogren's syndrome: an in vivo confocal study. Invest Ophthalmol Vis Sci. 2007 May; 48(5):2017-22. [PubMed: 17460255] 
220. Villani E, Viola F, Sala R, Salvi M, Mapelli C, Currò N, Vannucchi I, Beck-Peccoz P, Ratiglia R. Corneal involvement in Graves' orbitopathy: an in vivo confocal study. Invest Ophthalmol. 2010; 51(9):4574-8.

221. Villanueva O, Atkinson DS, Lambert SR. Trigeminal nerve hypoplasia and aplasia in children with goldenhar syndrome and corneal hypoesthesia. J AAPOS. 2005; 9(2):202-4. [PubMed: 15838455]

222. Walker JS. Anti-inflammatory effects of opioids. Adv Exp Med Biol. 2003; 521:148-60. [PubMed: 12617572]

223. Walker P, Weischel ME Jr, Fisher DA, Guo SM, Fisher DA. Thyroxine increases nerve growth factor concentration in adult mouse brain. Science. 1979; 204(4391):427-9. [PubMed: 441732]

224. Wang ZY, Alm P, Håkanson R. The contribution of nitric oxide to endotoxin-induced ocular inflammation: interaction with sensory nerve fibres. Br J Pharmacol. 1996; 118(6):1537-43. [PubMed: 8832083]

225. Wells J, Hurlbert RJ, Fehlings MG, Yong VW. Neuroprotection by minocycline facilitates significant recovery from spinal cord injury in mice. Brain. 2003; 126(7):1628-37. [PubMed: 12805103]

226. Wells, JR.; Michelson, MA. EyeNet Magazine. the American Academy of Ophthalmology; JulAug. 2008 Diagnosing and treating neurotrophic keratopathy. http://www.aao.org/publications/ eyenet/200807/pearls.cfm [Accessed online Dec. 2011.]

227. Wilson SA, Last A. Management of corneal abrasions. Am Fam Physician. 2004; 70(1):123-8. [PubMed: 15259527]

228. Wu Y, Chu RY, Zhou XT, Dai JH, Qu XM, Rao S, Lam D. Recovery of corneal sensitivity after laser-assisted subepithelial keratectomy. Journ Cat Refract Surg. 2006; 32:785-8.

229. Xu G, Pierson CR, Murakawa Y, Sima AA. Altered tubulin and neurofilament expression and impaired axonal growth in diabetic nerve regeneration. J Neuropathol Exp Neurol. 2002; 61(2): 164-75. [PubMed: 11855383]

230. Yamada N, Matsuda R, Morishige N, Yanai R, Chikama TI, Nishida T, Ishimitsu T, Kamiya A. Open clinical study of eye-drops containing tetrapeptides derived from substance $\mathrm{P}$ and insulinlike growth factor- 1 for treatment of persistent corneal epithelial defects associated with neurotrophic keratopathy. Br J Ophthalmol. 2008; 92(7):896-900. [PubMed: 18511539]

231. Yoon KC, Heo H, Im SK, You IC, Kim YH, Park YG. Comparison of autologous serum and umbilical cord serum eye drops for dry eye syndrome. Am J Ophthalmol. 2007; 144(1):86-92. [PubMed: 17493572]

232. Yoon KC, You IC, Im SK, Jeong TS, Park YG, Choi J. Application of umbilical cord serum eye drops for the treatment of neurotrophic keratitis. Ophthalmology. 2007 Sep; 114(9):1637-42. [PubMed: 17382396]

233. You L, Ebner S, Kruse FE. Glial cell-derived neurotrophic factor (GDNF)-induced migration and signal transduction in corneal epithelial cells. Invest Ophthalmol Vis Sci. 2001; 4:2496-2504. [PubMed: 11581189]

234. You L, Kruse FE, Volcker HE. Neurotrophic factors in the human cornea. Invest Ophthalmol Vis Sci. 2000; 41:692-702. [PubMed: 10711683]

235. Yu CQ, Rosenblatt MI. Transgenic corneal neurofluorescence in mice: a new model for in vivo investigation of nerve structure and regeneration. Invest Ophthalmol Vis Sci. 2007; 48(4):153542. [PubMed: 17389482]

236. Yu CQ, Zhang M, Matis KI, Kim C, Rosenblatt MI. Vascular endothelial growth factor mediates corneal nerve repair. Invest Ophthalmol Vis Sci. 2008; 49(9):3870-8. [PubMed: 18487369]

237. Zhao C, Lu S, Tajouri N, Dosso A, Safran AB. In vivo confocal laser scanning microscopy of corneal nerves in leprosy. Arch Ophthalmol. 2008 Feb; 126(2):282-4. [PubMed: 18268231]

238. Zhong J, Dietzel ID, Wahle P, Kopf M, Heumann R. Sensory impairments and delayed regeneration of sensory axons in interleukin-6-deficient mice. J Neurosci. 1999; 19:4305-13. [PubMed: 10341234]

239. Zöllner C, Mousa S, Klinger A, Förster M, Schäfer M. Topical fentanyl in a randomized, doubleblind study in patients with corneal damage. Clin J Pain. 2008; 24(8):690-6. [PubMed: 18806534] 


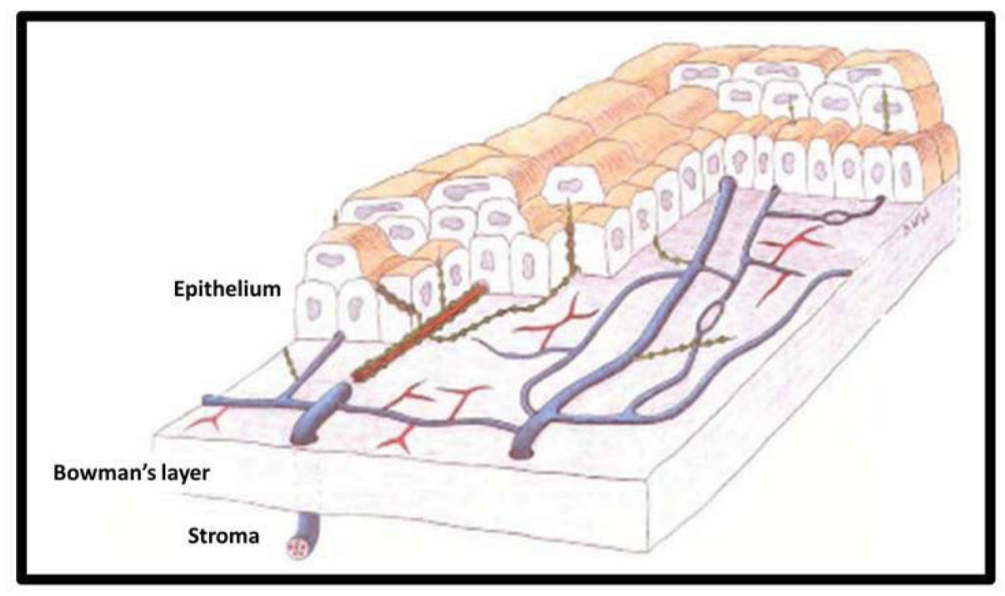

Figure 1.

Three-dimensional schematic of human corneal nerves. Stromal nerve bundles traverse Bowman's membrane to form the subbasal nerve plexus and innervate the epithelium. Unmyelinated nerve fibers (blue) bifurcate, and are composed of several straight (red) and beaded (green) nerve fibers. Beaded fibers branch orthogonally to terminate in free nerve endings in the anterior epithelium. Adapted from Müller et al. ${ }^{158}$ Copyright Association for Research in Vision and Ophthalmology. 

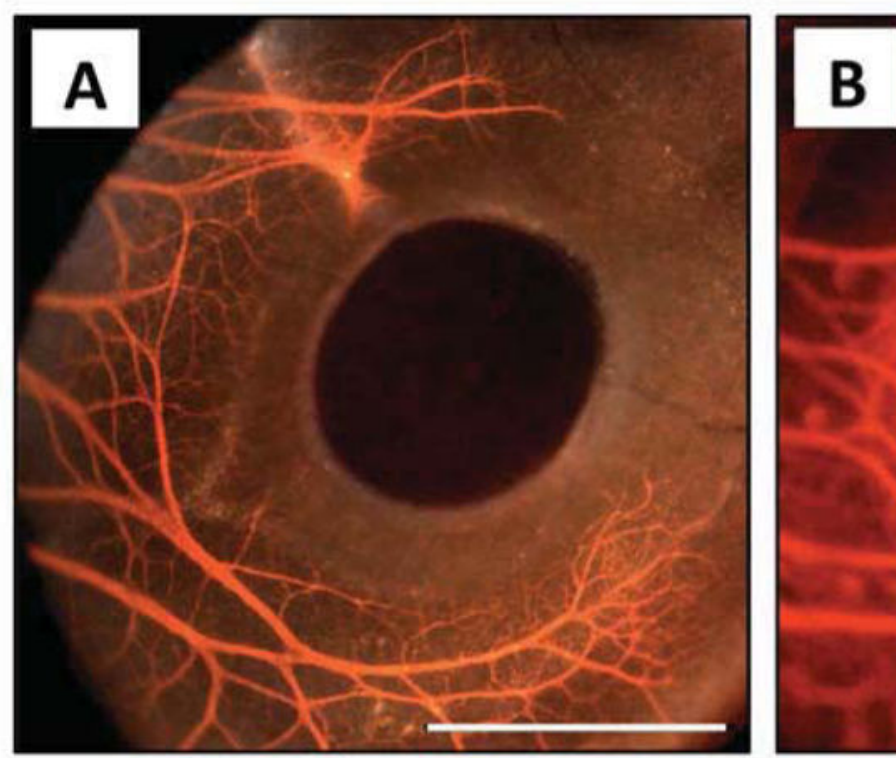

Figure 2.

Corneal nerves during development. A) Formation of the chick pericorneal nerve ring at embryonic day 6 (E6). Fluorescence image with brightfield overlay. B) Completion of the chick pericorneal nerve ring and subsequent penetration of corneal nerves into the stroma at E8. Fluorescence image only. Scale bar for A and B: $1 \mathrm{~mm}$. Courtesy of Dr. James K. Kubilus, Department of Anatomy and Cell Biology, Tufts University School of Medicine, Boston, MA. 113 


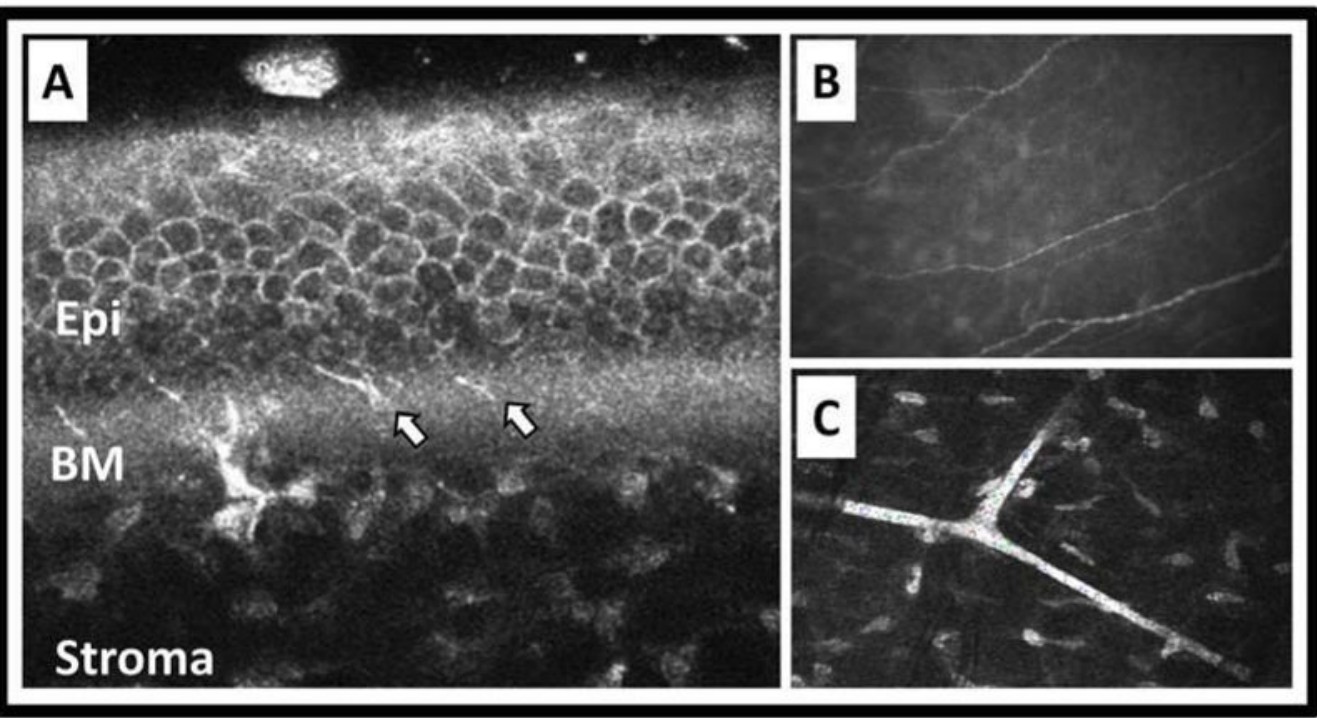

Figure 3.

In vivo imaging of corneal nerves. A) Heidelberg Retina Tomograph II with Rostock Corneal Module optical coherence tomography showing corneal nerves traversing Bowman's membrane (BM) to innervate the epithelium (Epi). Arrows point to nerves in the BM area. B and C) Nidek ConfoScan 4 slit-scanning confocal microscopy showing parallel nerves of the subbasal nerve plexus (B) and branching thick nerves of stroma (C). Courtesy of Heidelberg Engineering, Inc. and Nidek, Inc. 

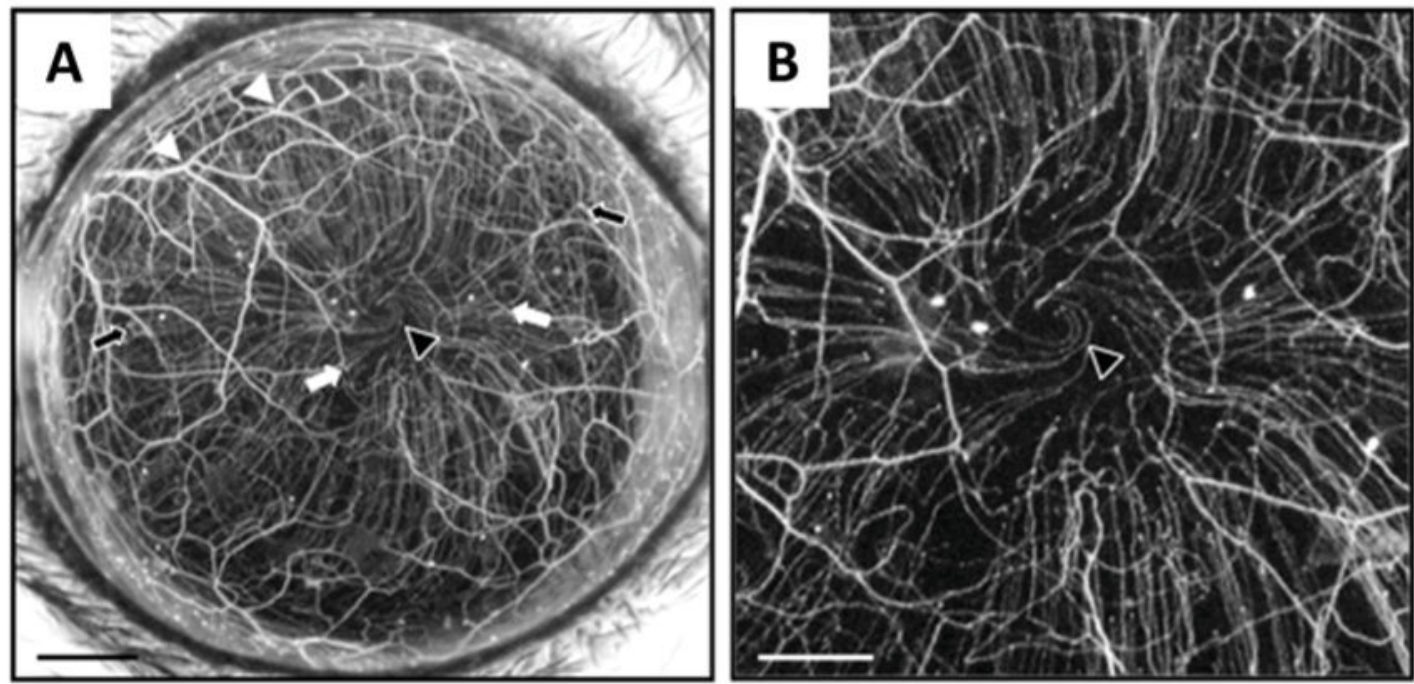

Figure 4.

In vivo maximum intensity projection image of fluorescent nerves in the normal thy1-YFP mouse cornea. A stromal network is formed by thick nerve trunks that traverse the cornea, branching frequently (white arrowheads) and anastomosing with adjacent nerve trunks. A second network is formed by thinner subbasal hairpin-like nerves that project centripetally and run roughly parallel to one another. The subbasal nerves arise from the stromal nerve trunks at variable distances from the periphery (black arrows indicate more peripheral origins and white arrows more central origins) and terminate as free nerve endings. In some corneas, the subbasal nerves show swirling at the corneal apex (black arrowhead). Intraepithelial nerves are not resolved with the stereo fluorescence microscope at the magnification used. Scale bar A, $500 \mu \mathrm{m} ; \mathrm{B}, 250 \mu \mathrm{m}$. 


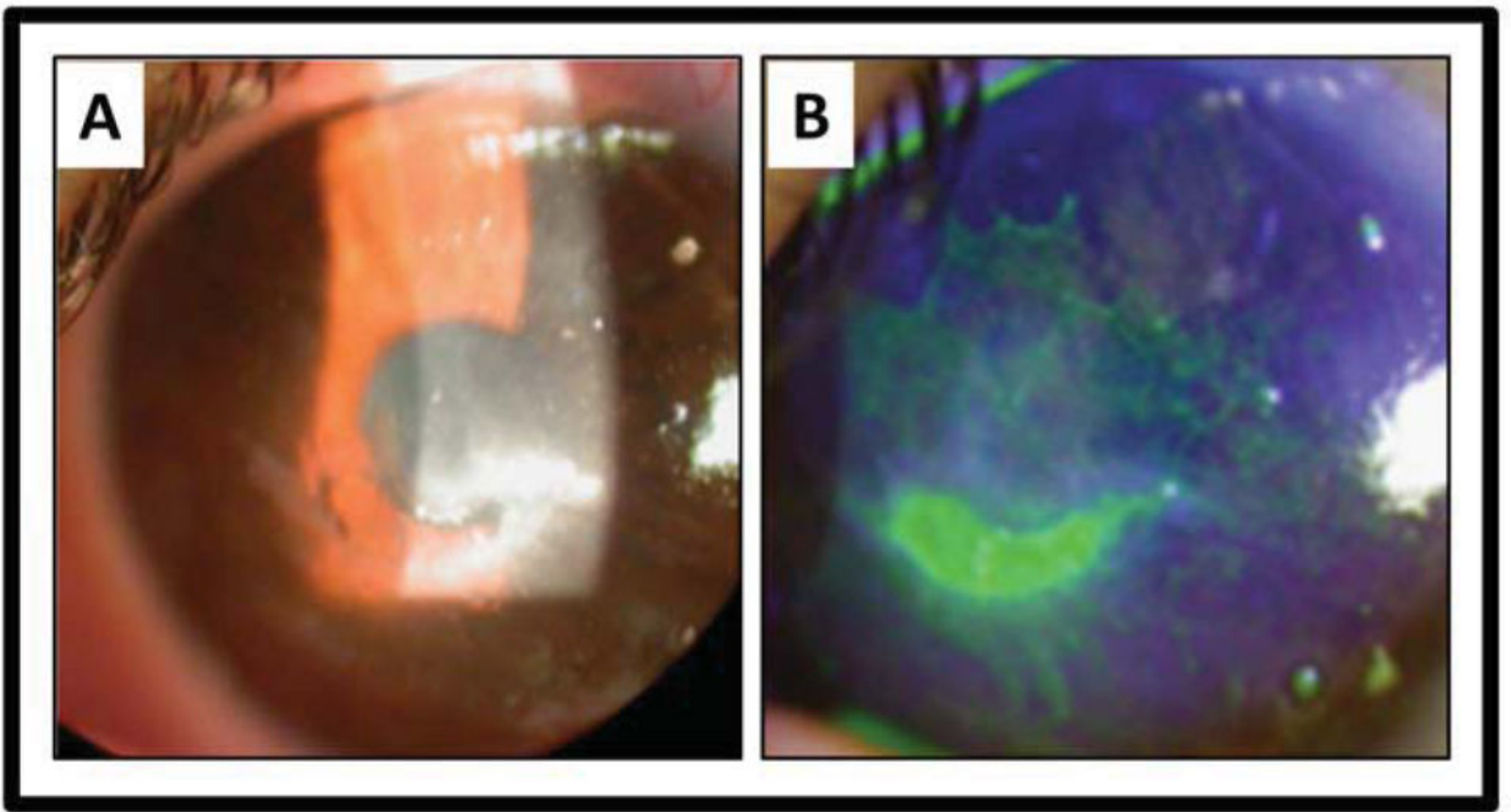

Figure 5.

Clinical photograph of a patient with neurotrophic keratitis. A) A central epithelial defect is surrounded by corneal haze. B) Fluorescein stains the central epithelial defect and reveals extensive superficial punctate keratitis. 


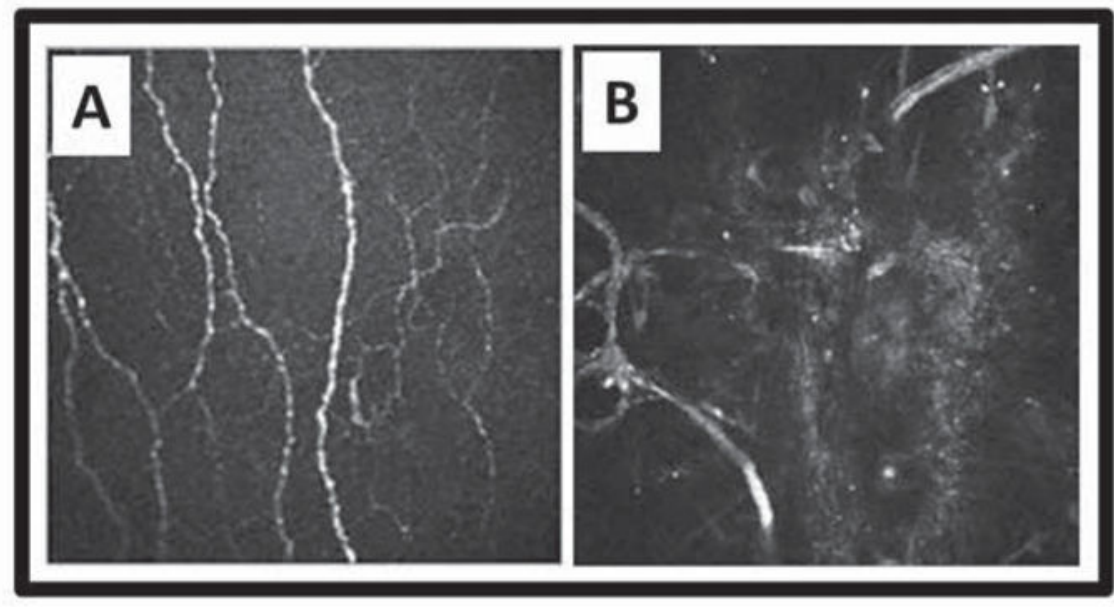

Figure 6.

Subbasal nerves before and after LASIK. Heidelberg Retina Tomograph II with Rostock Corneal Module optical coherence tomography showing subbasal corneal nerves A) before LASIK, and B) regenerated nerve loops in the flap area 4 years postoperatively. Courtesy of Heidelberg Engineering, Inc. and Dr. E.M. Messmer, Munich, Germany. 


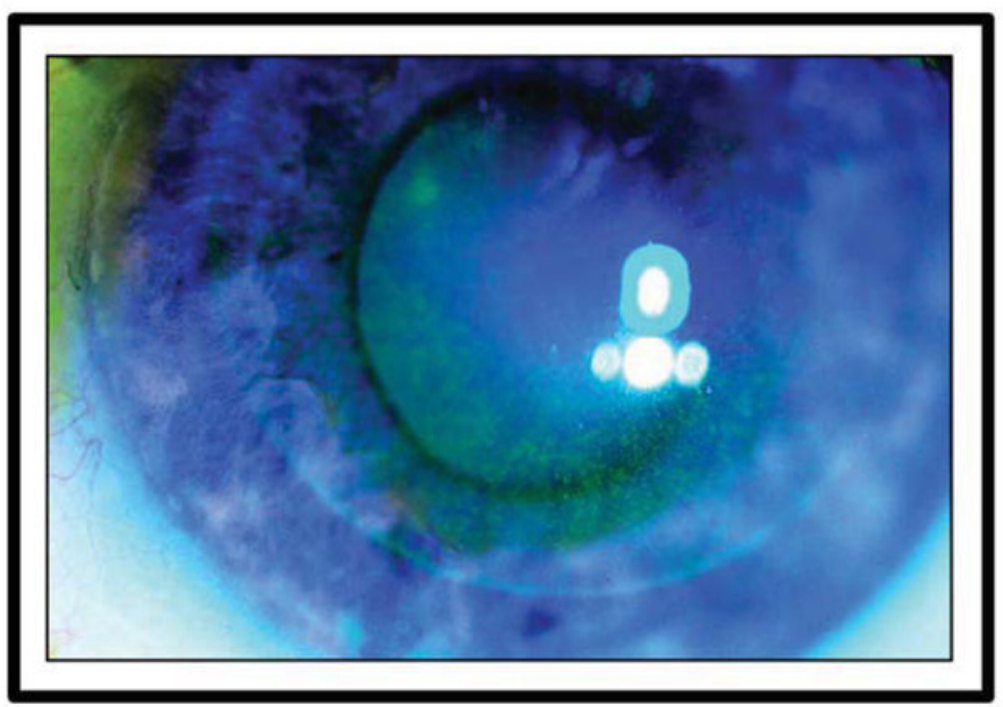

Figure 7.

Clinical photograph of a patient with LASIK-induced neurotrophic epitheliopathy (LINE). Superficial punctate keratitis stained with fluorescein is limited to the flap area of the cornea. 


\section{TABLE 1}

. Select neurochemical markers expressed in the cornea*

\begin{tabular}{|c|c|}
\hline Nerve fiber type & Associated markers \\
\hline Somatosensory (mechanical) & NF-200 165 \\
\hline \multicolumn{2}{|l|}{ Somatosensory (nociceptive) } \\
\hline \multirow[t]{5}{*}{ Peptidergic } & CGRP \\
\hline & SP \\
\hline & PACAP \\
\hline & Galanin \\
\hline & 156 \\
\hline \multirow{2}{*}{ Non-peptidergic } & FRAP \\
\hline & 156 \\
\hline \multicolumn{2}{|l|}{ Autonomic } \\
\hline \multirow[t]{4}{*}{ Sympathetic } & $\mathrm{NE}$ \\
\hline & 5-HT \\
\hline & NPY \\
\hline & 156 \\
\hline \multirow[t]{5}{*}{ Parasympathetic } & $\mathrm{ACh}$ \\
\hline & VIP \\
\hline & NPY \\
\hline & Galanin \\
\hline & 156 \\
\hline
\end{tabular}

NF-200 = neurofilament-200 kDa; CGRP = calcitonin gene-related peptide; SP = substance P; PACAP = pituitary adenylate cyclase-activating peptide; FRAP = fluoride-resistant acid phosphatase; $\mathrm{NE}=$ norepinephrine; $5-\mathrm{HT}=$ serotonin; $\mathrm{NPY}=$ neuropeptide $\mathrm{Y} ; \mathrm{ACh}=$ acetylcholine; VIP = vasoactive intestinal peptide.

In addition to these markers, the cornea contains neuropeptides of unspecified origin. These include cholecystokinin (CCK), neurotensin, brain natriuretic peptide (BNP), vasopressin, and $\beta$-endorphin. 156

Based on information obtained from human and animal models. 


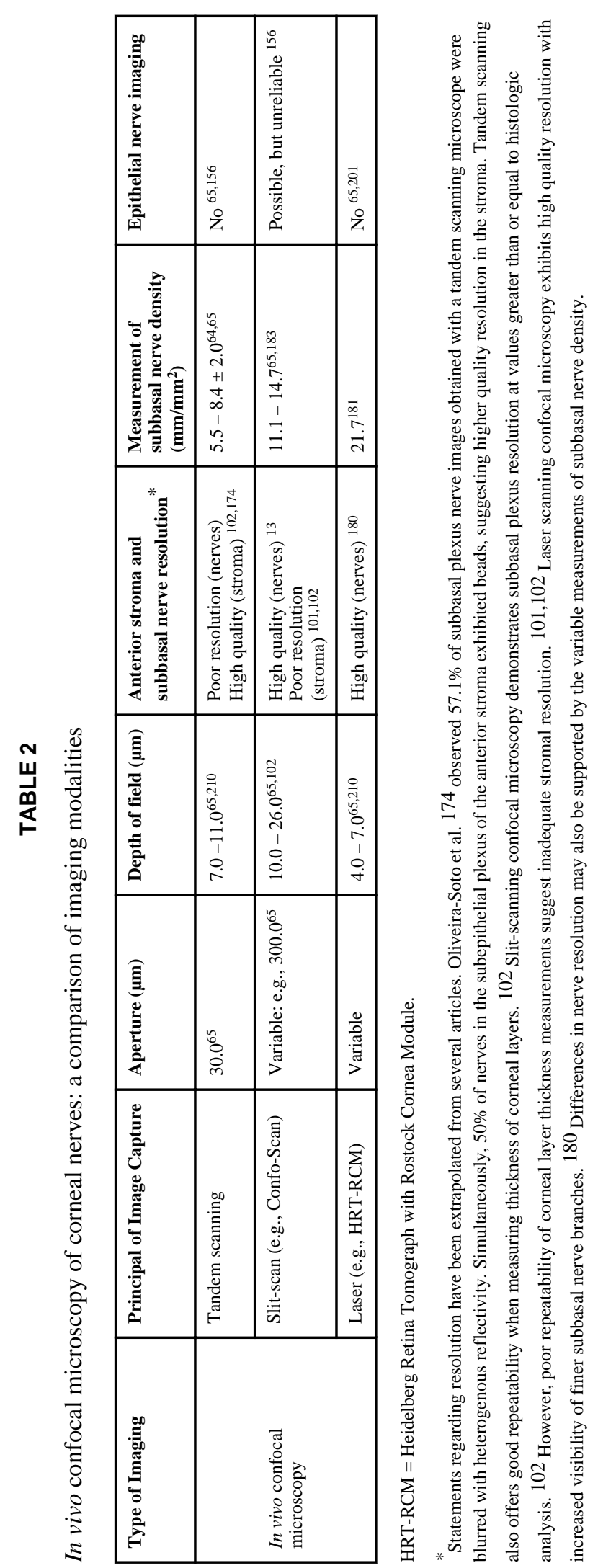

Surv Ophthalmol. Author manuscript; available in PMC 2015 May 01. 


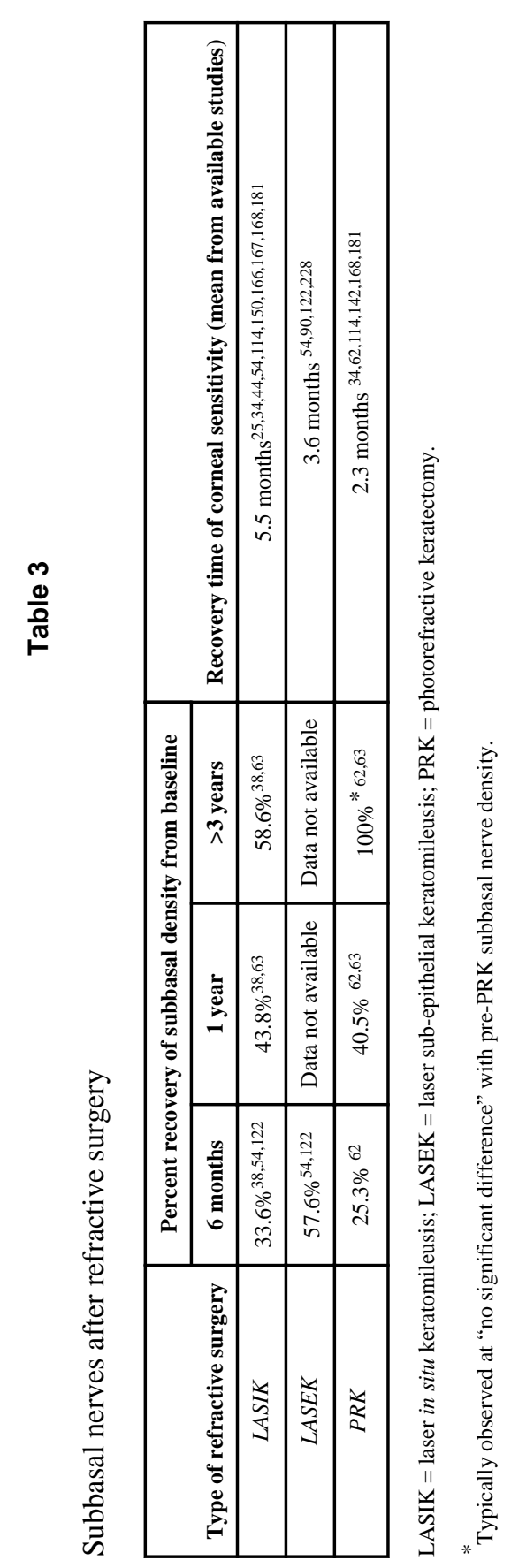

Surv Ophthalmol. Author manuscript; available in PMC 2015 May 01. 
TABLE 4

Modulators that affect neuronal as well as inflammatory pathways

\begin{tabular}{|c|c|c|}
\hline Factor & Effect on corneal nerves & Effect on inflammation \\
\hline \multicolumn{3}{|l|}{ Biological factors } \\
\hline NGF & Nerve regeneration 66 & Pro $36,120,129$ \\
\hline VEGF & Efficient regeneration 127 & Pro 99 \\
\hline DHA & Enhances regeneration 66 & Anti 49 \\
\hline PACAP & $\begin{array}{l}\text { Neurite outgrowth } \\
\text { Accelerates return of corneal sensitivity after injury }{ }^{76}\end{array}$ & $\operatorname{Pro}^{224}$ \\
\hline Slit2 & $\begin{array}{l}\text { Axonal repulsion (early development) }{ }^{113} \\
\text { Epithelial nerve branching (late development) }\end{array}$ & Anti 213 \\
\hline Sema7A & $\begin{array}{l}\text { Axonal elongation } \\
\text { Neurite outgrowth } \\
\text { Nerve regeneration } 164\end{array}$ & Pro ${ }^{164}$ \\
\hline T lymphocytes & Enhances regeneration 127 & Pro ${ }^{127}$ \\
\hline LIF & Accelerates regeneration 177 & Pro or anti ${ }^{189}$ \\
\hline IL-17 & Enhances regeneration ${ }^{127}$ & Pro ${ }^{127}$ \\
\hline \multicolumn{3}{|l|}{ Pharmacologic factors } \\
\hline Cyclosporine A & $\begin{array}{c}\text { Mixed: } \\
\text { Improved indirect measures of corneal nerve function }{ }^{5 *} \\
\text { Retards regeneration }{ }^{163}\end{array}$ & Anti 58,163 \\
\hline Corticosteroids & $\begin{array}{l}\text { Mixed: } \\
\text { May reverse neuropathic morphologies } 117 \\
\text { Improvement or no change in indirect corneal nerve function tests }{ }^{121} \text { * }\end{array}$ & Anti 121,125 \\
\hline Opioids & $\begin{array}{c}\text { Corneal reflex blockade } 218 \\
\text { Analgesia } 187\end{array}$ & Anti $222 \dagger$ \\
\hline Benzalkonium chloride & Neurotoxicity 197 & Pro 197 \\
\hline
\end{tabular}

$\mathrm{NGF}=$ nerve growth factor; VEGF $=$ vascular endothelial growth factor; DHA = docosahexanoic acid; PACAP = pituitary adenylate cyclaseactivating peptide; Sema7A = semaphorin 7A; LIF = leukemia inhibitory factor; IL-17 = interleukin 17. " - " = no known effect.

In these publications, corneal nerve function was measured indirectly by tests that assess elements of the nerve-epithelium-tear film axis, (such as Schirmer's, tear film breakup time, and/or fluorescent dyes for epithelial integrity), as well as subjective symptoms (such as dry eye and foreign body sensation)

${ }^{\dagger}$ Evidence supports the anti-inflammatory properties of kappa opioids, while the effect of other opioid classes on inflammation remains unclear. 